\title{
Mind the gap:
}

\section{Crowd-funding and the role of seed money ${ }^{1}$}

\author{
Joseph Deutsch, Bar-Ilan University, Ramat Gan, Israel \\ Gil S. Epstein, Bar-Ilan University, Ramat Gan, Israel, CReAM London and IZA, Bonn \\ Alon Nir, Bar-Ilan University, Ramat Gan, Israel
}

\begin{abstract}
We analyze voluntary private contributions to public goods and the role seed money plays in signaling the public good's quality to potential subsequent contributors. We present a theoretical model and analyze two sets of naturally occurring data from crowd-funding platforms. After developing the theoretical background we find statistically significant switch points which distinguish between seed contributions to subsequent contributions. A positive change in contribution behavior after the switch suggests an increase in the perceived value of the public good. We find that the signal comprises the number of contributors and the average contribution (as proportion of targeted goal).
\end{abstract}

JEL Classification: $\mathrm{H} 4, \mathrm{H} 42$,H8, D8

Key words: Crowd-funding platform, Voluntary Private Provision, Public Goods, Seed money

\footnotetext{
${ }^{1}$ We wish to thank Mr. Gregory Vincent for providing us with valuable data for the empirical analysis.
} 


\section{Introduction}

One of the most rigorously researched fields in economic literature is the field of public goods. In particular, research on the problem of financing the provision of public goods by voluntary private contributions has received considerable attention over the years. Failure to coordinate, the free rider problem, under provision of public goods and subsequent inefficiencies are just some of the plagues that researchers have been writing about extensively.

To this day, because of the difficulty in obtaining naturally-occurring data, empirical economic research in this field relies predominantly on laboratory experiments. However, recent technological developments, colloquially known as crowd-funding platforms and properly explained below, produce an abundance of naturally-occurring data. We obtained such data from two crowd-funding platforms, and seek to add to the existing literature by studying the dynamics of voluntary contributions to public goods as they are exhibited in the data. We focus on the role seed money (early contributions) plays in a public goods interaction and hypothesize it serves, as a signal of the public good's quality to less-informed potential subsequent contributors.

Over the past few years the World Wide Web has experienced the introduction and propagation of crowd-funding platforms (henceforth CFPs), which are websites for coordinating the collective raising of funds for a predetermined cause. These websites allow individuals and groups to post an initiative and seek funding for it from an online crowd comprising not only people in their social and professional circles but strangers as well. Contrary to traditional funding models in which an initiative (henceforth a project) is financed in full by a single or a few savvy investors, with crowd-funding many small contributions are solicited from a large crowd of supporters. These contributors (or backers) are commonly unskilled investors. ${ }^{2}$

How does it work? A campaign page on a crowd-funding platform is set up by a single or a small group of entrepreneurs (henceforth project owners or creators); they present the project they intend to execute and the purpose for which the funds will be used. This description is textual

\footnotetext{
${ }^{2}$ Not all crowd-funding platforms are alike, and they can be broadly categorized by the motivations to initiate or support a project. In some platforms, backers expect their contributions to yield a financial gain. These include platforms for investments in startups, microcredit for entrepreneurs and peer-to-peer lending. Other platforms facilitate various charities and causes to raise funds for their noble work. Finally, another type of platform is designed to support projects of various natures for neither monetary gain nor charity. These projects include - but are not limited to - creative endeavors, such as supporting a novice band making its first steps or aiding independent film creators to produce a movie. It is important to emphasize that backers of creative projects do not have the prospect of financial gain, shares, equity or intellectual property by supporting a project. Seemingly, they are driven by a desire to see the coming to life and completion of a project. Our research focuses on platforms of this type.
} 
and usually includes a video as well. The creators define a key factor: the amount of money they seek to raise for their project, or the project's goal. A time period for soliciting contributions is defined as well (generally up to 90 days). After the funding period concludes, the project is closed for further contributions whether the goal had been reached or not. Creators also specify perks, which are tokens of appreciation gifted to backers, depending on the amount they contribute.

During the active period of a project, owners attempt to solicit funds from their friends, families, colleagues and acquaintances, and spread the word about their project. Backers can contribute any amount they wish. In some platforms each individual contribution is displayed on the project's page, and in others, including the platform for which we have data, it is not. The project's page does clearly state the total contributions collected, the percent of goal attained and the number of backers that contributed to the project up to the point in time the page is visited. When the funding period concludes, one of three outcomes can occur: a. if total contributions meet or exceed the goal, the creators receive the funds and attend to working on the project. Excess contributions can be used, for instance, to produce a higher quality version of the project (e.g., a band can record its album using more sophisticated equipment). b. If the goal was not met, the outcome is contingent on the specific platform's refund rule. Some platforms operate under an allor-nothing rule, where all contributions are refunded, and other platforms, like the one we explore, have a keep-it-all rule, which allows owners to keep whatever was raised.

Crowd-funding platforms are tools for collecting voluntary contributions from individuals for the financing of public goods (henceforth $P G$ s). Coordinating contributions and eliciting cooperative behavior from agents pose major challenges in this realm, due to free riding behavior, assurance problems or missing information regarding the quality of the PG. For example, Samuelson (1954) proclaimed an economy cannot achieve the Lindahl solution as it is in the best interest of each individual to signal he has less interest in consuming the PG than he indeed has. Neither taxes nor user prices are a viable or efficient solution to this asymmetric information problem (Hillman, 2009).

A sequential protocol of play (a key characteristic of CFPs) appears to alleviate some of these cooperation problems. For example, Erev and Rapoport (1990) and Coats et al. (2009) found there was a significantly higher level of provision of the PG and greater efficiency in the sequential protocol compared to the simultaneous. Coats et al. (2009) also add the role of a refund to the 
comparison between simultaneous and sequential protocols of play. They find that guaranteeing a refund in case the provision threshold is not met is effective in countering the assurance problem in a simultaneous setting. ${ }^{3,4,5}$

The term seed money refers to early contributions to the PG from a single or small group of people (also known as 'leadership giving' or 'leadership contributions'). Andreoni (1998) proposed a model where the threshold PG game is divided into two stages: a leadership stage and a contribution stage. At the first stage, a small subset of the population, identified as possible leaders, is asked to pledge funds to the PG. ${ }^{6}$ Afterwards, the amount contributed by the leaders is announced and the general public is asked to (simultaneously) contribute to the PG. The purpose of the leadership stage is to attempt to raise enough seed money so that followers would be interested to provide the required funds to reach the provision threshold. Furthermore, the leadership stage provides some assurance to the followers by eliminating the zero contribution Nash equilibrium. Andreoni proposes each individual holds a personal threshold, which is "the amount of exogenous giving at which person $i$ is just willing to bring the PG up to the threshold value by acting alone". A person with a low threshold can be thought of as more generous, while a high threshold suggests the person is conservative or prudent. In a seminal paper Granovetter (1978) suggested a similar concept for describing collective social behavior.

Bracha et al. (2011) empirically tested Andreoni's (1998) claims in the lab, with a simplified two player setting. They find support for the theory for a high threshold. Sequential play enables cooperative behavior, eliminates inefficient outcomes, and increases the likelihood of reaching the provision threshold, in contrast to the simultaneous case where players mostly fail to obtain it. Furthermore, the authors find that the effect of sequential moves is greater in the presence of a threshold compared to the lack thereof.

\footnotetext{
${ }^{3}$ Schmidtz (1987) proposed a conditionally binding assurance contract, under which players commit to contribute to the PG and are billed if and only if the total amount committed by all players meets the provision threshold. Brubaker (1975) suggested similar contracts can even elicit individuals' true valuations of the PG. An all-or-nothing refund rule is de facto the CFPs' equivalent of an assurance contract.

${ }^{4}$ For more on refunds, see, for example, Palfrey \& Rosenthal (1984), Cadsby \& Maynes (1999).

${ }^{5}$ The mirror image of the fear to squander resources due to being futile is the fear of being redundant, that is to contribute funds when the provision threshold for a discrete good was reached by others' contributions. The respective mechanism to address this concern is a rebate rule. However, the setting we research includes sequential moves and common knowledge of the total sum of available resources. Hence a discussion of rebate rules is superfluous. Indeed, we are unaware of a CFP that offers a rebate. For more on rebates see Marks \& Croson (1998) and Spencer et al. (2009).

${ }^{6}$ Note that being a leader is voluntary. A person approached at the leadership stage can refrain from contributing and effectively allocate herself to the followers group. Hence, a person is a leader only if she is better off as one.
} 
In a PG setting there is often a problem of asymmetric information, in which potential contributors do not have full information of the true quality of the PG at the time they make their contribution decision. Modeling for the job market, Spence (1973) proposed that problems of asymmetric information can be overcome if the knowledgeable party sends a signal to the uninformed party. Andreoni (2006) explored a model which centers on the signaling role early contributions play. He depicts a setting in which the knowledgeable party makes a public contribution that signals the quality of the PG to the followers. This contribution in fact provides two public goods: information on the quality and the project itself.

Potters, Sefton and Vesterlund $(2005,2007)$ experimentally explored a two player setting, where one player is informed about the quality of the PG and the other is not. Their results indicate that with her contribution, the informed player can credibly signal the quality of the PG. The uninformed players tended to mimic the decisions of the informed (the effect was negligible when the quality was common knowledge), a response that was anticipated by the latter. In addition, when the quality was known only to the leader and her contribution was not announced, the follower rarely contributed.

Empirical research based on naturally-occurring data or data collected in field experiments is rather scarce in the economic literature. List et al. (2002) utilized 3,000 households, segmented to different experimental treatments. The authors found that increasing the announced seed money dramatically increased both the participation rate and the average amount donated. Another controlled field experiment, carried by Frey \& Meier (2004) in the University of Zurich, found students were more likely to make a contribution to social funds when informed of a higher contribution rate of students before them. These results are in line with Granovetter (1978) and Andreoni’s (1998) suggestions of threshold motivated behavior.

As online CFPs have emerged only in recent years ${ }^{7}$, related literature is nascent and scarce. However, researchers' interest in crowd-funding appears to be on the rise. ${ }^{8}$ Agrawal et. al (2013) provide a good introduction to the basic characteristics of crowdfunding as well as the advantages and disadvantages this mechanism offers to backers and creators. By contributing to a

\footnotetext{
${ }^{7}$ Kappel (2009) identifies Sellaband, established in 2006, to be the first of the kind, yet CFPs became widespread only in the past few years as of the time of this writing.

${ }^{8}$ A large part of the current literature looks into aspects of crowd-funding different from what is of interest to us, such as a financial perspective or legal issues concerning this type of financing.
} 
crowdfunding project backers face risks of creator incompetence, fraud and project failure. These are exacerbated by the high degree of information asymmetry between backers and creators. Since contributions to a crowdfunding project are small and personal gains are low, an individual is less motivated to perform due diligence on the project and instead may adopt decisions made by earlier contributors. Therefore, contributors are subject to herding behavior. According to the authors, accumulated funds raised to a project can serve as a signal of quality, with the caveat that it will reflect true project quality only if early contributors carefully examine benefits and risks associated with the project. Furthermore, the information cascade from early contributors to the latter can be manipulated if project creators inject capital in early funding stages. Quality indicators, such as previous successful ventures or level of education may also signal quality in an asymmetric information setting. The authors also reaffirm the provision threshold as a mean to counter collective action pitfalls.

Agrawal et al. (2011) analyzed a data set from Sellaband (www.sellaband.com), a CFP for musicians. They identified friends and family as the early supports of projects and suggest these early investments serve as a signal to latter supporters. Furthermore, they found the average distance between artists and their supporters on the Sellaband platform is about 5,000 km, showing the large potential crowd of supporters a crowd-funding project has. Lambert and Schwienbacher's (2010) main finding is evidence suggesting non-profit crowd-funding initiatives tend to be more successful than for-profit initiatives. Zhang and Liu (2012) study an online microloan platform where lenders face the risk borrowers will default on their loan. They find evidence of rational herding among lenders, where they infer the creditworthiness of a borrower by observing previous lenders' decisions and interpret them in the context of publicly stated borrower characteristics.

We start by presenting a theoretical model for the signaling role of early contributions in public good interactions with asymmetric information. We show that the production threshold can be met or even exceeded depending on the signal the informed player sends with her contribution and the way it is interpreted by the uninformed follower. Outcomes with zero and partial contributions are shown as well. We analyze two sets of naturally occurring data from two crowdfunding platforms - one set is uniquely granular with information on each individual contribution made on the platform, while the set from the second platform is much larger in size but only includes daily aggregates of contributions. In the empirical analysis, we are able to differentiate 
between early and latter contributions in our data set, and see that the average contribution and average number of backers rise after seed money has been given. We find that the signal seed contributions convey comprises two components: the number of contributors of seed money and the average contribution they provide, in terms of proportion of fund raising goal.

\section{A Model}

In this section, we propose a model that captures the interaction on CFPs. We build upon two public good game models introduced by Potters et al. (2005, 2007). Two players (Player 1 and Player 2), play a single shot sequential public goods game. They both need to allocate an endowment of 1 between a private good and the public good. $x_{i}$ is the contribution of player $i$ to the provision of the public good, $i=1,2$. Player 1 moves first, and Player 2, which observes Player 1's decision, follows.

The PG cannot go into production unless the combined contributions of Player 1 and Player 2 are equal to or greater than $T$. Excess contributions above $T$ are neither rebated nor wasted (the PG is continuous after $T$ ). If the PG does not go into production, the contributions are not refunded. The value of $T$ is common knowledge. We assume $T \leq 2$ for feasibility and that $T>1$, that is, no player can finance the production of the PG without the cooperation of the other player. ${ }^{9}$ The production function is given by:

$$
f\left(x_{1}, x_{2}\right)=\left\{\begin{array}{lll}
\sqrt{x_{1}+x_{2}} & \text { if } & x_{1}+x_{2} \geq T \\
0 & & \text { otherwise }
\end{array}\right.
$$

If the provision threshold is met, each player receives a payoff of $m$ per unit of the PG produced $(m>0) .{ }^{10} m$ is determined exogenously and can be thought of as representing the quality of the PG produced. Player $i$ 's profit is given by:

$$
\pi_{i}=\left\{\begin{array}{lrr}
1-x_{i}+m \sqrt{x_{1}+x_{2}} & \text { if } & x_{1}+x_{2} \geq T \\
1-x_{i} & \text { otherwise }
\end{array}\right.
$$

\footnotetext{
${ }^{9}$ The concept of crowd-funding is to replace large contributions by a single entity with smaller contributions from multiple supporters.

${ }^{10}$ Cases where $m \leq 0$ are trivial and of little interest.
} 
Both players are profit maximizers. It is easy to see Player 1 will contribute to the PG only if she believes the production threshold will be met, and Player 2 will not contribute unless he sees that his contribution will make the total contributions meet or exceed the threshold. If a player does not contribute to the PG, the entire endowment is spent on consuming the private good and the player gains a profit of 1 .

We assume Player 1 has perfect information regarding the value of $m$, while Player 2 is oblivious to it. ${ }^{11}$ Player 2 therefore attempts to infer it from Player 1's contribution, which serves him as a signal. We assume the following form to represent Player 2's expected value of $m$ :

$$
m^{e}=\varphi_{j}\left(\frac{x_{1}}{T}\right)^{1 / 2}, \quad j=L, H
$$

Player 2's assessment is based on two factors: the proportion of the threshold covered by Player 1's contribution $x_{1} / T$ (taken at its squared root value) and a parameter $\varphi_{j}$ which can be thought of as Player 2's sensitivity to the signal. We assume Player 2 can be one of two types: one with a Low sensitivity to the signal, denoted by $\varphi_{L}$, or a High sensitivity, denoted by $\varphi_{H}\left(j=L, H, \varphi_{L}<\right.$ $\left.\varphi_{H}\right)$.

After both players make their contributions the game ends, and if total contributions amount to $T$ or more, the PG is produced and the players receive their payoffs. We proceed to solve the leader-follower sequential interaction with backward induction. Since Player 2 is oblivious to $m$, his aim is to maximize his expected profit. From (2) and (3) we can obtain his expected profit:

$$
\pi_{2, j}^{e}=1-x_{2, j}+\varphi_{j}\left(\frac{x_{1}}{T}\right)^{\frac{1}{2}} \sqrt{x_{1}+x_{2, j}}, \quad j=L, H
$$

Differentiating $\pi_{2, j}^{e}$ with respect to $x_{2, j}$ and setting the derivative to zero yields the first order condition, from which we can obtain Player 2's best response (BR) function:

$$
x_{2, j}^{*}=\frac{x_{1}\left(\varphi_{j}^{2}-4 T\right)}{4 T}, \quad j=L, H
$$

\footnotetext{
${ }^{11}$ In CFPs the project owners typically inform their close social circles first, and may not even know latter contributors (a claim supported by the findings of Agrawal et al. (2011)). This personal relationship can explain why the first contributor is better informed in our model.
} 
It can be verified that the second order condition holds. ${ }^{12}$

Player 1 does not know Player 2's type and resorts to assigning probabilities to the likelihood of either type. $P_{L}$ represents the assigned probability Player 2 is of type $L$, and $P_{H}$ is the assigned probability Player 2 is of type $H, P_{H}=1-P_{L}$. Therefore, Player 1 seeks to maximize her expected profit:

$$
E \pi_{1}=1-x_{1}+m\left[P_{L} \sqrt{x_{1}+x_{2, L}}+P_{H} \sqrt{x_{1}+x_{2, H}}\right]
$$

After plugging in (5) for $j=L, H$ we can obtain Player 1's optimal contribution:

$$
x_{1}^{*}=\frac{m^{2}}{16 T}\left[P_{L} \varphi_{L}+P_{H} \varphi_{H}\right]^{2}
$$

It can be verified that the second order conditions holds.

By (7) and (5) we obtain:

$$
x_{2, j}^{*}=\frac{m^{2}\left(\varphi_{j}^{2}-4 T\right)\left[P_{L} \varphi_{L}+P_{H} \varphi_{H}\right]^{2}}{64 T^{2}}, j=L, H
$$

The derivatives of $x_{1}^{*}$ and $x_{2, j}^{*}$ with respect to $T$ are negative, which means that a higher threshold has a negative effect on contributions from both players. A higher threshold weakens the signal sent by Player 1's contribution (see (3)), thus lowering $x_{2, j}^{*}$. This affects Player 1 as well, as she plugs Player 2's best response function into her expected payoff. We see there's a tradeoff between setting a goal to raise a large amount (for a big project) and the likelihood of reaching it.

The derivatives of $x_{1}^{*}$ and $x_{2, j}^{*}$ with respect to the sensitivities to the signal, $\varphi_{L}$ and $\varphi_{H}$, and the expected value of the sensitivity $\left[P_{L} \varphi_{L}+P_{H} \varphi_{H}\right]$ are positive. This means that as the sensitivity and the expected sensitivity of Player 2 increase, Player 1 is more willing to contribute to the PG. Thus she is not trying to free-ride off Player 2, but cooperate. Player 2, in turn, reciprocates. The

\footnotetext{
${ }^{12}$ We set $\varphi_{j}>\sqrt{4 T}$, and as we can see in (5) for all $\varphi_{j} \leq \sqrt{4 T}$ Player 2 will not contribute to the PG at all (of course, his contribution cannot be negative in case that $\varphi_{j}<\sqrt{4 T}$ ). That is, if Player 2's sensitivity to the signal is weak, the expected quality of the PG is too low to contribute.
} 
derivatives of $x_{1}^{*}$ and $x_{2, j}^{*}$ with respect to $P_{L}$ are negative, and positive when differentiating with respect to $P_{H}$.

It can be shown that if their combined contributions $\left(x_{1}^{*}, x_{2, j}^{*}\right)$ are sufficient for the PG to go into production the players expect to be better off contributing to the PG than consuming just the private good. ${ }^{13}$ However, Player 1 will not contribute unless she expects contributions to meet or exceed $T$. That is, Player 1 has the following contribution condition:

$$
x_{1}^{*}+E x_{2, j}^{*} \geq T, \quad j=L, H
$$

We shall now explore the different scenarios resulting from condition (9) separately. ${ }^{14}$

\section{Case I - Condition (9) holds}

If the condition in (9) holds, Player 1 will contribute according to her optimal choice given in (7). If Player 2's best response to $x_{1}^{*}$ brings the combined contributions to $T$ or more, the game's outcome is $\left(x_{1}^{*}, x_{2, j}^{*}\right)$ or (remember $(7)$ and $\left.(8)\right)$ :

$$
\left(\frac{m^{2}}{16 T}\left[P_{L} \varphi_{L}+P_{H} \varphi_{H}\right]^{2}, \frac{m^{2}\left(\varphi_{j}^{2}-4 T\right)\left[P_{L} \varphi_{L}+P_{H} \varphi_{H}\right]^{2}}{64 T^{2}}\right), \quad j=L, H
$$

The PG is produced and there may even be overprovision. ${ }^{15}$

However, condition (9) pertains to Player 1's beliefs, and even if the condition is satisfied it is not guaranteed that the sum of contributions given by the players' optimal values (10), will indeed be equal to or greater than $T$. In case that Player 1's expectations fall short of reality, that is (9) holds yet total contributions would be less than $T$, there could be two possible outcomes. Foreseeing that by contributing $x_{2, j}^{*}$ as a response to $x_{1}^{*}$ will not bring total contributions to the threshold, Player 2 can either:

\footnotetext{
${ }^{13}$ Appendix A1.3 presents expressions to the expected and actual payoffs under each outcome of the model.

${ }^{14}$ We make a plausible assumption that Player 1 does not know Player 2's endowment. She does expect Player 2 to have the resources to complement her contribution to $T$. It can be shown that relaxing this assumption brings complexity into our analysis without affecting the qualitative findings or adding value.

${ }^{15}$ Note that when $\varphi_{j}<\sqrt{8 T}$ Player 1's contribution is greater than Player 2's, and consequently her actual payoff is smaller, despite having the leader's advantage and perfect knowledge of the quality of the PG. When $\varphi_{j}>\sqrt{8 T}$ Player 2's contribution is greater and his payoff is smaller.
} 
(i) contribute nothing $-x_{2, j}=0$. The PG will not be produced, Player 1's contribution will be wasted and she will gain $1-x_{1}^{*}<1$. Player 2 will gain 1 , from consuming the private good. In this case, the outcome of the game is:

$$
\left(\frac{m^{2}}{16 T}\left[P_{L} \varphi_{L}+P_{H} \varphi_{H}\right]^{2}, 0\right)
$$

(ii) contribute $x_{2, j}^{\prime}>x_{2, j}^{*} \cdot x_{2, j}^{\prime}$ is the amount that will complement $x_{1}^{*}$ exactly to $T$, thus bringing the PG into production. Since Player 2 needs to contribute more than his best response to $x_{1}^{*}$, his expected profit declines as his contribution becomes greater than $x_{2, j}^{*}$. Hence, if Player 2 chooses (ii) he will bring the total contributions to equal exactly $T$. Therefore, we can express $x_{2, j}^{\prime}$ as:

$$
x_{2, j}^{\prime}=T-x_{1}^{*}=T-\frac{m^{2}}{16 T}\left[P_{L} \varphi_{L}+P_{H} \varphi_{H}\right]^{2}, \quad j=L, H
$$

Player 2 will choose (ii) if his expected profit under this option is at least 1 . This will bring the game's outcome to be:

$$
\left(\frac{m^{2}}{16 T}\left[P_{L} \varphi_{L}+P_{H} \varphi_{H}\right]^{2}, T-\frac{m^{2}}{16 T}\left[P_{L} \varphi_{L}+P_{H} \varphi_{H}\right]^{2}\right)
$$

Figure 2a in the Appendix illustrates the different outcomes of the case when condition (9) holds.

Case II - Condition (9) does not hold

In case condition (9) does not hold, Player 1 will of course not contribute $x_{1}^{*}$ as given by (7). She can contribute zero and consume solely the private good. From (3) it is straightforward the in this case Player 2 will infer the PG is worthless and will not contribute anything either (furthermore, he cannot finance the production by itself). The outcome will be $(0,0)$. However, even that contributing $x_{1}^{*}$ is not optimal when (9) does not hold, the PG can still be provisioned, or even over-provisioned. Player 1 may choose to contribute $x_{1}^{\prime}>x_{1}^{*} . x_{1}^{\prime}$ is the amount for which Player 1 believes the expected value of Player 2's optimal response would be to exactly complement her contribution and reach $T$. Since $x_{1}^{\prime}>x_{1}^{*}$ it is against Player 1's best interest to contribute any amount that would lead total contributions to be greater than $T$. In the Appendix we show that: 


$$
x_{1}^{\prime}=\frac{4 T^{2}}{P_{L} \varphi_{L}^{2}+P_{H} \varphi_{H}^{2}}
$$

This contribution can yield several responses from Player 2. If Player 2's true sensitivity to the signal is equal to or greater than Player 1's estimation, then indeed Player 2's best response contribution would bring total contributions to meet or exceed the threshold $T$, respectively. Even in case that Player 2's sensitivity to the signal is less than Player 1's estimation, the PG can still be provided. As we've seen under the first scenario, Player 2 may choose to exactly complement Player 1's contribution to the production threshold, by contributing an amount greater than what his best response function suggests. We discuss these outcomes in the Appendix, and illustrate them in Figure $\mathbf{2 b}$ in the Appendix.

To conclude, our model has numerous outcomes, which correspond to observations we have in our set of naturally-occurring data (see section 3). We see outcomes where total contributions exceed the production threshold, as well as several scenarios where contributions equal exactly the value of $T$. Furthermore, the model has outcomes where the PG is not provisioned at all. This can occur when both players contribute nothing or when Player 1 contributes a portion of what's required to meet the production threshold, yet Player 2 does not respond.

\section{Empirical Analysis}

\subsection{The data}

The empirical analysis was carried on two data sets from two crowd-funding platforms. We began by analyzing a uniquely granular set of naturally-occurring data of crowd-funding campaigns from one of Europe's largest CFPs, UK based Sponsume. ${ }^{16}$ Afterwards we analyzed a larger, albeit less detailed, set of data from one of the world's leading crowdfunding-platforms, Kickastarter ${ }^{17}$, in order to test the validity of our findings.

Between its inception in April 2011 and September 2012, Sponsume hosted 662 crowdfunding projects on its platform. We obtained a detailed log of all the contributions made for these

\footnotetext{
${ }^{16}$ www.sponsume.com
}

${ }^{17}$ www.kickstarter.com 
projects, which specifies the amount, time and date, and project contributed to for each of the contributions (approximately 15,500 overall). ${ }^{18}$ This level of granularity could only be made possible with the assistance of the platform's owners. Furthermore, for each project we obtained data that include its name, the target goal, the total amount raised, number of backers (contributors to the project), the date on which the project was made publicly available on the CFP (henceforth the start date) and the date the contribution came to an end (henceforth the end date), number of perk tiers and their value, project category, the number of words, paragraphs and links the project creator used to describe it. Certain calculations were performed on the data in order to add more measures to our data set. For example, the success ratio of the project was generated by dividing the amount raised by target goal, and the average contribution to the project by dividing the total amount raised by number of backers. Descriptive statistics for these projects are given in Table 1.

\begin{tabular}{|l|l|r|r|r|r|r|r|r|}
\cline { 3 - 8 } \multicolumn{2}{c|}{} & Obs. & \multicolumn{1}{c|}{ Mean } & \multicolumn{1}{c|}{ SD } & \multicolumn{1}{c|}{ Min } & \multicolumn{1}{c|}{ Max } & Median & Mode \\
\hline \multirow{4}{*}{ Goal (GBP) } & All projects & 662 & 3970.62 & 9736.71 & 150 & 200000 & 2000 & 1000 \\
\cline { 2 - 9 } & Successful Projects & 176 & 2086.48 & 2776.50 & 150 & 25000 & 1200 & 1000 \\
\cline { 2 - 9 } & Unsuccessful Projects & 486 & 4652.94 & 11165.58 & 166 & 200000 & 2500 & 1000 \\
\hline \multirow{3}{*}{$\begin{array}{l}\text { Funds Raised } \\
\text { (GBP) }\end{array}$} & All projects & 662 & 1047.86 & 1931.20 & 0 & 27301 & 453.5 & 20 \\
\cline { 2 - 9 } & Successful Projects & 176 & 2335.34 & 3028.12 & 200 & 27301 & 1477.5 & 1000 \\
\cline { 2 - 9 } & Unsuccessful Projects & 486 & 581.61 & 977.23 & 0 & 10828 & 272.5 & 20 \\
\hline \multirow{3}{*}{$\begin{array}{l}\text { Success } \\
\text { Ratio* }\end{array}$} & All projects & 662 & 0.47 & 0.49 & 0 & 4.22 & 0.2506 & 1 \\
\cline { 2 - 9 } & Successful Projects & 176 & 1.15 & 0.33 & 1 & 4.22 & 1.0478 & 1 \\
\cline { 2 - 9 } & Unsuccessful Projects & 486 & 0.22 & 0.23 & 0 & 0.9828 & 0.1342 & 0.04 \\
\hline \multirow{2}{*}{$\begin{array}{l}\text { Number of } \\
\text { Backers }\end{array}$} & All projects & 662 & 23.52 & 30.94 & 0 & 386 & 14 & 2 \\
\cline { 2 - 9 } & Successful Projects & 176 & 45.00 & 36.01 & 1 & 214 & 35 & 23 \\
\cline { 2 - 9 } & Unsuccessful Projects & 486 & 15.74 & 24.67 & 0 & 386 & 9 & 2 \\
\hline $\begin{array}{l}\text { Average } \\
\text { Contribution } \\
\text { (GBP) }\end{array}$ & All projects & 662 & 45.10 & 66.08 & 0 & 1000 & 30.30 & 10 \\
\cline { 2 - 9 } & Successful Projects & 176 & 54.65 & 54.52 & 8.59 & 561.8 & 39.28 & 30 \\
\cline { 2 - 9 } & Unsuccessful Projects & 486 & 41.64 & 69.53 & 0 & 1000 & 27.64 & 10 \\
\hline
\end{tabular}

Table 1. Descriptive statistics for crowd-funding projects in our data set. *Success Ratio defined as Funds Raised (GBP) divided by Goal (GBP).

We can see from Table 1 that only about $27 \%$ of crowd-funding campaigns managed to reach or exceed the amount they set out to raise, the goal. Projects which were unsuccessful at reaching their goal (henceforth unsuccessful projects) set a goal 2.23 times greater on average than successful projects, with an average of $£ 4652.94$ compared to $£ 2086.48$ respectively. Successful projects, however, raised on average 4 times the amount of unsuccessful projects, with $£ 2,335.34$

\footnotetext{
18 The contribution log was provided to us after it was anonymized, so identifiable personal information about the people who contributed to campaigns (henceforth backers) was not disclosed.
} 
and $£ 581.61$ respectively. Furthermore, not only did successful projects manage to cultivate nearly 3 times more backers, the average contribution itself per backer was higher for successful projects, with $£ 54.65$ for successful projects and $£ 41.64$.

Sponsume is home to projects of cultural and artistic nature. Project creators are required to categorize their project prior to publishing it on the CFP, and 243 projects in the data set $(36.7 \%)$ were categorized as Film or Documentary, and another 158 projects (23.86\%) were posted under the Performing Arts category. Other popular categories for projects include Music (60 projects, 9.03\%) and Fine Arts (42, 6.34\%). A frequency table for project categories can be found in Appendix B1.

Initial analysis of the data revealed a dichotomy in the success ratios of projects which reached or passed their goal and those that failed to do so. Figure 1 plots the cumulative relative frequency of success ratios in the data set. Each dot represents a success ratio that at least one project in the data set achieved. For example, it can be easily seen that $60 \%$ of projects had a success ratio of $40 \%$ or lower. The figure reveals that the distribution of success ratios is not uniform. We also see that at about $60 \%$ success ratio the graph begins to level off until it reaches the $100 \%$ mark, and that between these two points observations become more scarce.

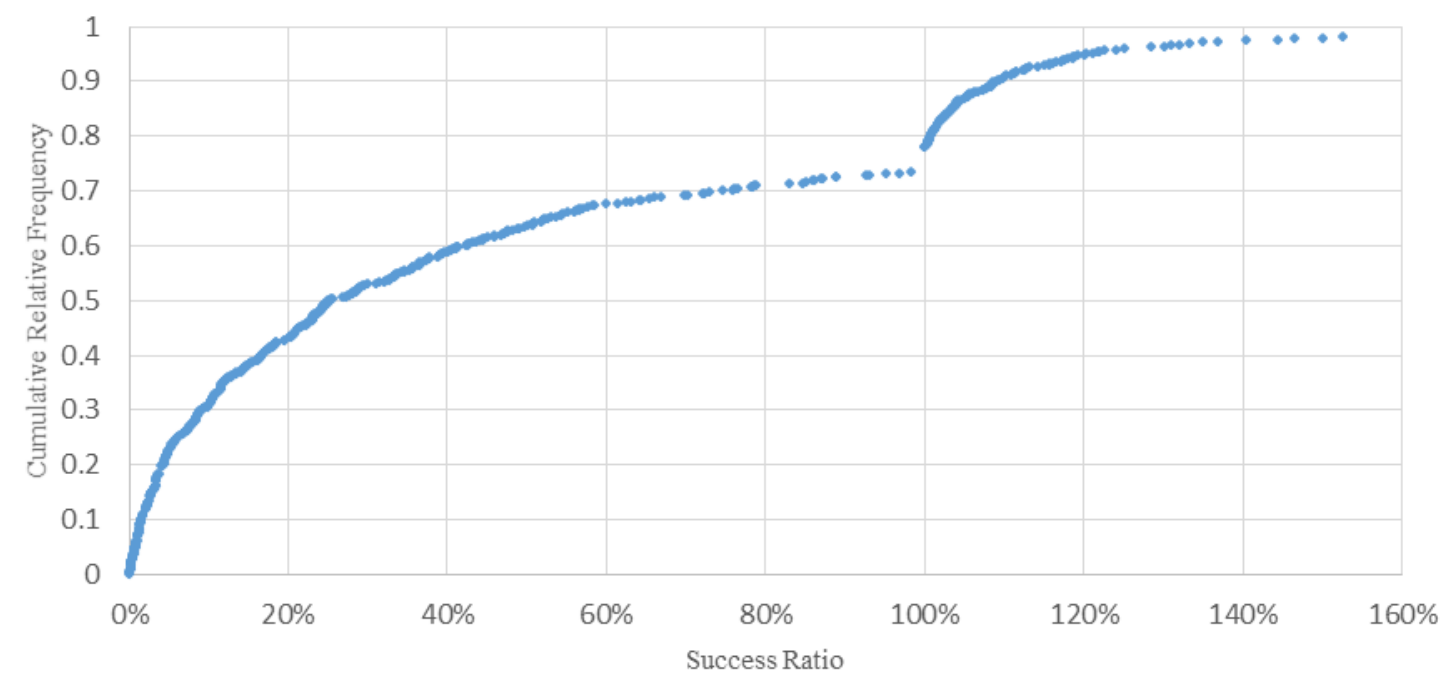

Figure 1. Cumulative relative frequency of success ratios. For ease of presentation, the horizontal axis was trimmed at $160 \%$, dropping 10 projects with higher success ratios.

According to the data, $90.12 \%$ of unsuccessful projects (66.16\% of all projects) raised less than $55 \%$ of their goal, and one half of all unsuccessful projects raised $13.33 \%$ or less of their goal. 
23 projects (3.47\% of all projects) raised nothing at all. On the other hand, among the 176 successful projects, 30 reached exactly $100 \%$ of their goal, (17.04\% of successful) and the overall average success ratio of successful projects stands at approximately $115 \%$.

Our second set of data, obtained from an online project that scraped Kickstarter's website periodically, was less detailed and granular, but much larger in scope. Unlike the Sponsume data set, which detailed each and every contribution made, this data set provided daily snapshots of the aggregate amount contributed and the number of backers. To the best of our knowledge, to this day neither Kickstarter nor Indiegogo ${ }^{19}$ (the biggest CFP other than Kickstarter) released data with per-contribution granularity, or any such data became otherwise available online. Furthermore, compared to the Sponsume data set it included less information describing the projects themselves, such as the perk tiers. The advantage of the data set is in its size - it contains 18,808 campaigns, out of which 9,095 successful, categorized under Art, Documentary, Theatre, Photography, Film and Music. These data exhibited similar characteristics as the small set - more than $97 \%$ of unsuccessful campaigns raised less than 55\% of their goal. Figure 3 in Appendix B4 plots the cumulative relative frequency of success ratios, where we again see the graph levelling off around the $60 \%$ success ratio, persisting until the 100\% mark. Table 6 in Appendix B3 provides descriptive statistics for these projects.

This dichotomy, the gap between success ratios of unsuccessful and successful projects shows that for the most part, projects in our data set which passed a certain threshold of funds raised relative to their goal, moved on to reach or exceed their goal. This finding provides initial indication for the effect seed money has on successfully reaching the goal. We shall henceforth use the term switch point to refer to this threshold, a certain proportion of goal which distinguishes between seed money and subsequent contributions, and after which the contribution pattern changes behavior. The switch point distinguishes between the contributors themselves as well backers before the switch point fit our description of leaders, and backers after the switch point the followers.

\footnotetext{
${ }^{19}$ www.indiegogo.com
} 


\subsection{Method}

The analysis of the data was performed in two stages. First, we used Quandt's method (1958) to find switch points, if they exist. Then we took the statistically significant switch points and regressed them against various variables in order to find which, if any, affect the switch point.

Quandt (1958) suggested a procedure to determine where a switch from one regime to another occurs in a linear regressions system which obeys two separate regimes. A procedure which automatically runs Quandt's method required projects to have 15 backers or more in order to perform accurately (we chose to use the 15 as presented in the literature) and therefore projects with fewer backers were dropped from our data set. Deutsch (1992) provides an empirical distribution for Quandt's statistic, which we used in order to examine the statistical significance of the switch point.

All in all, 348 projects had less than 15 backers; 324 were unsuccessful projects and 24 were successful. ${ }^{20}$ Further 26 projects had to be discarded as careful examination of the data revealed potential data corruption for one or more key variables to our analysis, which could not be corrected. The remaining 287 (143 successful, 144 unsuccessful) projects successfully passed rigorous data validation testing. Descriptive statistics on these projects (see Appendix B2) show they are qualitatively similar to the projects in the full set.

The procedure ran on the remaining projects and its output consisted the switch point, given in terms of the proportion of goal and the ordinal number of the backer where the switch occurred. The intercepts and slopes of the two lines and the likelihood ratio statistic value to determine the statistical significance of the switch point were also reported.

To illustrate the results of the method, Figure 2 depicts the progress and switch point of a project in our data set, and the linear lines that fit the before and after the switch distribution of observations.

\footnotetext{
${ }^{20}$ The successful projects that were dropped can be generally described as small projects. 15 of the 24 set out to raised 500 GBP or less, and another 7 targeted sums between 500 and 1000 GBP.
} 


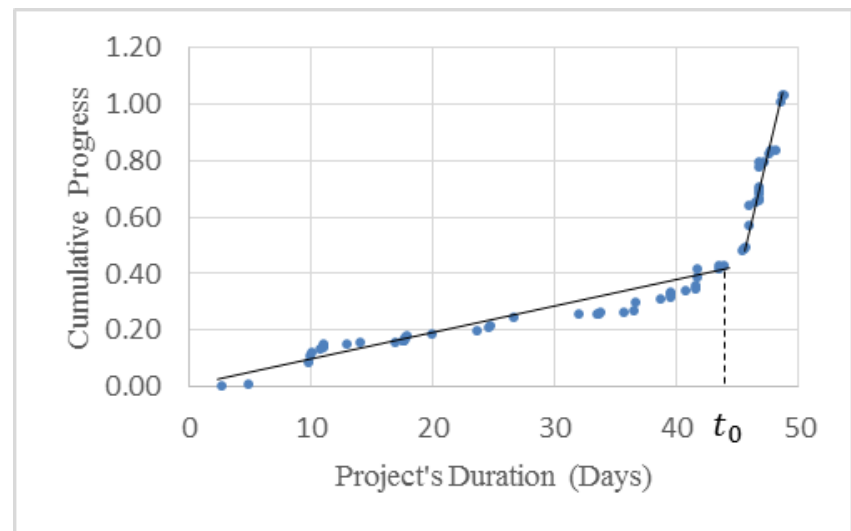

Figure 2. The switch for the project depicted here for example occurred after $42.8 \%$ of the goal was achieved.

After identifying the switch points, we performed calculations using our data sets and created new measures for each of the projects that relate to pre and post switch performance. These include, for example, the average contribution before and after the switch (in GBP and as proportion of goal), the number of backers before and after the switch and the ratio between the two, the amount raised before and after the switch (GBP), the time passed since the start date and until the switch in terms of days and proportion of total project span. These measures are presented and discussed below.

We performed a standard linear regression on the switch point against a large group of possible explanatory variables. We first regressed the switch point in successful projects, and by using an iterative process found the set of variables that have a statistically significant effect on the dependent variable. Table 3 shows the results of this regression. We then regressed the switch points of the unsuccessful projects against the same set of independent variables (Appendix B7). A logistic regression on a binary variable which indicates a success or a failure at reaching or passing the goal, and a standard linear regression with success ratio as the dependent variable were also carried out. Their results are given in Table 12 and Table 13 in the Appendix. After thoroughly researching the detailed smaller data set, we ran the same procedure on the larger data set, as much as the granularity of the data allowed, in order to test our findings.

\subsection{Results}

For all but seven projects the switch point was statistically significant at the $5 \%$ significance level, and at the $10 \%$ level just one project did not have a statistically significant 
switch point. We removed this sole project from further analysis and continued with 286 projects, 142 successful and 144 unsuccessful. The average goal set for unsuccessful projects is about 1.8 times greater than that for successful projects. The average amount raised in successful projects, however, is over twice that in unsuccessful projects. The average number of backers in successful projects is nearly 51 compared to nearly 36 in unsuccessful projects, and the average contribution is $36.31 \%$ higher for successful projects in GBP terms. From a proportion of goal perspective, the average contribution in a successful project is about $3.22 \%$ of the goal, 2.28 times of the mere $1.41 \%$ in unsuccessful projects. We see that successful projects substantially outperform the failed ones, not just in overall terms but also on the backers' participation level.

Analyzing the statistically significant switch points shows the mean value of the switch point for successful projects is $54.88 \%$ of the goal, and the median is $52.25 \%$, with the majority of switch points falling between $25 \%$ and $75 \%$ of goal. For unsuccessful projects, the mean is $18.03 \%$ and the median is $14.7 \%$. Descriptive statistics about the switch points can be found in Appendix B5. Figure $4 \mathrm{a}$ and Figure $4 \mathrm{~b}$ in the Appendix show histograms for the distribution of switch points for successful and unsuccessful projects respectively.

These results are consistent with our prior observation that most projects which reached this proportion of their goal managed to reach the $100 \%$ mark or pass it. The average switch point for unsuccessful projects is at roughly $18 \%$ of the goal, which is less than a third of the average switch point for successful projects. It is interesting to note that the average success ratio for unsuccessful projects is $39.83 \%$. This means that the average value of the switch point for successful projects is higher than the average percent of goal raised in unsuccessful projects during the entire campaign. ${ }^{21}$

Next we discuss pre and post switch behavior. Table 2 highlights results of the analysis. ${ }^{22}$ First, we see that the average contribution grew substantially after the switch in both successful and unsuccessful projects. For successful projects the average post switch contribution was about $80 \%$ higher than the average contribution before the switch, and for unsuccessful projects it was

\footnotetext{
${ }^{21}$ Furthermore, consider that since we dropped projects with less than 15 backers from the analysis, we artificially inflated the average success ratio of the unsuccessful projects by eliminating projects which performed particularly poorly. If we hadn't eliminated these projects from the analysis, the average success ratio of all unsuccessful projects would be $21.91 \%$ - about half that of the projects we discuss (note that the average success ratio for successful projects would remain nearly unchanged, with an average of $115.46 \%$ ).

${ }^{22}$ Table 8 in the Appendix reports more pre and post switch measures.
} 
about $61 \%$ higher on average (although the difference is not statistically significant). Before the switch, the average contribution for successful projects is $£ 42.98$ compared to $£ 32.45$ for unsuccessful, and in terms of proportion of goal the average contribution is over twice as high for successful projects with $2.87 \%$ of goal, versus an average of $1.24 \%$ of goal for unsuccessful projects. After the switch, the average contribution increases for both groups with averages of $£ 66.51$ and $£ 42.19$ for successful and unsuccessful projects, respectively, which are $4.06 \%$ of goal for successful projects, and merely $1.67 \%$ for unsuccessful projects. Furthermore, the ratio calculated by dividing the number of backers after the switch by number of backers before it is 1.29 and 1.36 on average for successful and unsuccessful projects respectively (the difference is not statistically significant). This result indicates that the number of backers after the switch grew at about $30 \%$ on average for both groups.

It is interesting to look at the slopes of the two regression lines. b0 represents the slope of the line before the switch and b1 the slope of the line after. Remember that the horizontal axis represents the days of projects' span (each unit represents one day, that is a 24 hour period; half a unit represents 12 hours, and so on), and the vertical axis show the cumulative proportion of goal attained. The slope, therefore, can be thought of the velocity of the progress - the percent of goal obtained per time unit. We can see that the slope of the line prior to the switch is more than 6.5 greater for successful projects on average (an average of 0.12 for successful projects and 0.018 for unsuccessful). Put differently, successful projects head towards the switch point at a substantially higher velocity than unsuccessful projects. After the switch, the average slope of the successful projects decreases to 0.103 while for unsuccessful projects the average increases to 0.024 , hence the average velocity remains substantially higher for successful projects after the switch. The data reveal that for 77 of 142 successful projects $(54.22 \%)$ b1 is greater than b0, which is also the case for 60 of 144 unsuccessful projects in our analysis (41.66\%). Therefore, we can see that in more than half the cases the slope of successful projects in fact increases, while for almost $60 \%$ of unsuccessful projects it decreases. 


\begin{tabular}{|l|l|l|l|}
\hline & Successful & Unsuccessful & All \\
\hline Number of backers before the switch* & 142 & 144 & 286 \\
\hline Number of backers after the switch* & 27.72 & 17.42 & 22.53 \\
& $(25.09)$ & $(17.26)$ & $(22.08)$ \\
\hline Backers after the switch/before the switch ratio & 23.15 & 18.30 & 20.71 \\
& $(20.67)$ & $(22.17)$ & $(21.54)$ \\
\hline Average contributions before the switch GBP* & 1.29 & 1.36 & 1.32 \\
& $(1.23)$ & $(1.07)$ & $(1.15)$ \\
\hline Average contributions before the switch as proportion of goal* & 0.0287 & 0.0124 & 0.0205 \\
& $(0.0200)$ & $(0.0103)$ & $(0.0178)$ \\
\hline Average contributions after the switch GBP* & 66.52 & 42.19 & 54.27 \\
& $(68.54)$ & $(32.95)$ & $(54.93)$ \\
\hline Average contributions after the switch as proportion of goal* & 0.0407 & 0.0168 & 0.0286 \\
& $(0.0288)$ & $(0.0157)$ & $(0.0260)$ \\
Average contribution after the switch-before the switch ratio & 1.79 & 1.61 & 1.70 \\
& $(1.62)$ & $(1.41)$ & $(1.52)$ \\
\hline b0 - Slope of first line* & 0.1201 & 0.0183 & 0.0689 \\
& $(0.30)$ & $(0.04)$ & $(0.22)$ \\
\hline b1 - Slope of the second line* & 0.1039 & 0.0248 & 0.0641 \\
& $(0.25)$ & $(0.11)$ & $(0.20)$ \\
\hline
\end{tabular}

Table 2. Key measures for successful and unsuccessful projects. Standard deviations are in parenthesis. * indicates the difference between means is statistically significant at the $5 \%$ significance level.

At the next stage of the analysis we carried out standard linear regressions on the switch points of successful projects against a list of potential explanatory variables. Through an iterative process we found the set of variables that have statistically significant coefficients. The results of this regression are presented in Table 3. We see that the average contribution before the switch in terms of proportion of goal and the number of backers before the switch have a large effect on the switch point. An additional 1 unit in average contribution before the switch as proportion of goal would increase the switch point by 20.77 units on average. That is to say, an increase of 1 percent of goal in the average contribution before the switch as proportion of goal would increase the switch point by 0.2077 or $20.77 \%$ of goal. An additional backer before the switch would increase the switch point by $2.05 \%$ of goal, on average. Any contribution can be thought of as the subjective valuation of the project and the desire to see it coming to fruition, and so a higher average contribution may signal a higher quality. A greater number of backers signals that more people share this average valuation, perhaps also making it more accurate in subsequent backers' view. A greater number of backers also signals that more people are interested in seeing this project 
succeeds and are committed to it, thereby signaling high quality. The coefficient of the squared values of these two variables is negative and the effect is statistically significant, which shows the diminishing marginal effect increases in average contribution as proportion of goal and number of backers have on the switch point. Put differently, increases in their values would not increase the switch point indefinitely. Sufficiently high values of these variables would decrease the switch point. That is, very strong signals will even bring about the switch at a lower percentage of the goal.

As the regression reveals, there are other factors that affect the size of the switch point, yet their effect is miniscule compared to the two factors above. One is total contributions in the first two days of the campaign as proportion of goal, where a $1 \%$ increase would increase the switch point by $0.2 \%$ of goal, on average. The direction of this effect makes sense as, ceteris paribus, a greater proportion of goal achieved in the first two days increases the overall proportion of goal achieved. The proportion of time it took for the switch to occur as a proportion of the entire project span (Days to switch as proportion of span) has an even smaller effect. The positive sign is reasonable, as with more time to raise contributions prior to the switch, more contributions can be accepted, hence increasing the proportion of goal achieved and the switch point. The target goal, in GBP, has a negligible negative effect. The negative sign is plausible since a higher goal means that a given contribution in GBP makes out a smaller proportion of goal. The GBP values of the highest and median perks have a negligible effect as well. A possible explanation to the effect and its positive sign could be that some of the backers adjust their contributions to the perk tiers, and so higher GBP values for perks increase the total contributions and in turn the proportion of goal at the switch point. ${ }^{23}$

We proceeded with regressions on the switch point of unsuccessful projects. Outputs of the regressions are presented in Appendix B7. The main finding from the regression on the unsuccessful projects is that for them as well, the switch point is best explained by the average contribution before the switch as proportion of goal and the number of backers. The coefficients are somewhat smaller than in the regression on successful projects. An increase in the average contribution before the switch as proportion of goal of 1 percent of goal would increase the switch

\footnotetext{
${ }^{23}$ Note that the correlation between the goal in GBP and the GBP value of the highest valued perk is very weak $(\rho=-0.03)$ and the correlation between the goal in GBP and the GBP value of the median valued perk isn't strong either $(\rho=0.31)$. The correlation matrix can be found in Appendix B8.
} 
point by $16.9 \%$ of goal on average, and an additional backer before the switch would increase the switch point by $0.84 \%$ of goal, on average. However, these are still the factors we identified with the greatest effect on the switch point. The coefficients of the squared values of these variables are negative here as well, indicating a diminishing marginal effect. A plausible explanation to the smaller coefficients is that since the switch point for unsuccessful projects occurs after accumulating relatively small proportion of goal (about $18 \%$ on average, a third of the average in successful projects), the effect is limited in size.

\begin{tabular}{|c|c|c|c|c|c|c|}
\hline switch point & Coef. & Std. Err. & $\mathrm{t}$ & $\mathrm{P}>|\mathrm{t}|$ & $\begin{array}{l}{[95 \%} \\
\text { Conf. }\end{array}$ & Interval] \\
\hline $\begin{array}{l}\text { Average contribution before the } \\
\text { switch as proportion of goal }\end{array}$ & $20.77751^{*}$ & 2.07252 & 10.03 & 0 & 16.67786 & 24.87716 \\
\hline $\begin{array}{l}\text { Average contributions before the } \\
\text { switch as proportion of goal } \\
\text { squared }\end{array}$ & $-115.5458 *$ & 19.01607 & -6.08 & 0 & -153.1615 & -77.93015 \\
\hline Backers before the switch & $0.0205233^{*}$ & 0.0012531 & 16.38 & 0 & 0.0180447 & 0.023002 \\
\hline Backers before the switch squared & $-0.0000754^{*}$ & $6.97 \mathrm{E}-06$ & -10.82 & 0 & -0.0000892 & -0.0000617 \\
\hline $\begin{array}{l}\text { Total contributions in first two } \\
\text { days as proportion of goal }\end{array}$ & $0.225387 *$ & 0.063303 & 3.56 & 0.001 & 0.1001674 & 0.3506066 \\
\hline Goal GBP & $-0.0000194 *$ & $5.67 \mathrm{E}-06$ & -3.41 & 0.001 & -0.0000306 & $-8.13 \mathrm{E}-06$ \\
\hline $\begin{array}{l}\text { Days to switch as proportion of } \\
\text { span }\end{array}$ & $0.1083324 *$ & 0.0397002 & 2.73 & 0.007 & 0.0298015 & 0.1868633 \\
\hline Value of highest perk GBP & $2.66 \mathrm{E}-09 *$ & $1.29 \mathrm{E}-09$ & 2.06 & 0.041 & $1.11 \mathrm{E}-10$ & 5.20E-09 \\
\hline Value of the median perk GBP & $0.000864 *$ & 0.0004021 & 2.15 & 0.033 & 0.0000686 & 0.0016594 \\
\hline cons & $-0.4552568 *$ & 0.060783 & -7.49 & 0 & -0.5754915 & -0.3350221 \\
\hline
\end{tabular}

Table 3. A linear regression on successful projects' switch points. Coefficients marked by * are statistically significant at the 5\% significance level. Adjusted $R^{2}=80.19 \%$.

The findings for unsuccessful projects reinforce our claims. We found statistically significant switch points for all unsuccessful projects in our data set, after which there's a change in contribution behavior as the average contribution rises after the switch (both in terms of GBP and proportion of goal) and the number of backers increases as well, on average. In the case of unsuccessful projects, the performance before and after the switch was not strong enough to reach the target goal, yet the overall finding that there's a positive change in contribution behavior after a certain threshold, and that the number of backers and average contribution in terms of proportion 
of goal best explain this threshold, holds true. It is also interesting to note that the goal unsuccessful projects set was on average 1.8 times greater than the goal successful projects set. Recall that in the theoretical model we showed that a higher goal weakens the signal and make success harder to achieve.

There are several factors that arguably may affect a project's performance, switch point and overall chances of success that were not included in our empirical investigation. For some of these we have no data, and others may not even be quantifiable at all. Examples for the former include the size of the social network project creators have prior to launching the campaign, i.e. the number of family members, friends and colleagues they can promote their project to at the beginning (and throughout) the campaign. An example to the latter could be the creators' reputation and the influence they have on their social circles, which is to say how likely are people in their social network to contribute to the campaign and how much. Other factors could be the number of visitors the creators managed to generate to their campaign page (by means such as word of mouth, public relations campaigns, etc.), past experience running crowd-funding campaigns, reputation in the relevant industry, a proven track record and so on. These factors may also explain the strong start we identified in successful projects relative to unsuccessful projects.

Finally, we used the data for successful and unsuccessful projects to carry more analysis. We ran a logistic regression on a binary variable which indicated success or failure at reaching the goal in a campaign, and a standard linear regression where overall success ratio served as the dependent variable. The results of these regressions (see Appendix B9) provide further affirmation to the effect the number of backers before the switch and the average contribution as proportion of goal have on overall project performance.

Running the same procedure on the larger data set reaffirmed our findings from analyzing the smaller data set. As the program required 15 data points or more per project, and the data was aggregated to daily snapshots, 7,441 projects were analyzed. Of these, merely 75 did not have a statistically significant switch points at the 5\% significance level. The mean value of the switch point for successful projects stands at $64.81 \%$ and the median at $55.31 \%$ (13.69\% and $11.19 \%$ for unsuccessful projects, respectively). Of the set of significant explanatory independent variables the regression on the successful projects in the smaller set found, we had all but those relating the perks in the larger set. Linear regressions on the switch points reaffirmed our findings qualitatively, 
specifically with a positive and marginally diminishing effect for number of backers and average contribution in terms of proportion of goal. Adjusted $R^{2}$ values were lower than the ones received regressing the Sponsume data $(57.3 \%$ for successful projects and $70.9 \%$ for unsuccessful, compared to $80.1 \%$ and $84.5 \%$, respectively), which is plausible due to the loss of granularity in the Kickstarter data. Results of these regressions can be found in Table 14 and Table 15 in Appendix B10.

\subsection{Discussion}

The empirical analysis of the naturally-occurring data we obtained substantially supports our theoretical hypothesis. The analysis indicates projects' performance and overall success are subject to seed money effect, as early contributions to a campaign affect the subsequent. This effect is carried out by the signal early contributions send, which comprises two components: the number of backers and the average of their subjective evaluation of the project (as indicated by the average contribution, given in terms of proportion of goal). Average contribution and the average number of backers increased after the seed money was collected. This indicates an increase in willingness to contribute and greater confidence in the project's quality and the campaign's chances of reaching the goal and providing the good.

We arrived at the empirical analysis after hypothesizing that early contributions to a crowdfunding campaign send a signal to potential subsequent contributors about the quality of the project. We obtained a unique data set of naturally-occurring data from a real world crowd-funding platform, consisting of 662 projects. We found that unsuccessful campaigns fell substantially short of their goal, as about $94 \%$ of them raised less than $2 / 3$ of their target and one half raised $13.33 \%$ or less. A similar phenomena was found in a much larger data set we also considered.

We used Quandt's method (1958) to identify at what point during a project's progress a switch occurred (if at all), after which the contribution pattern obeyed a different regime. For all but one of the 287 projects examined a statistically significant switch point was found, thus supporting our distinction between seed contributions and latter contributions. For successful projects a switch occurred at approximately 55\% of the target goal on average (the median was $52.25 \%$ ). This sits well with our aforementioned observation. After the switch, average contribution in successful projects rose, from $£ 42.98$ or $2.87 \%$ of goal prior to the switch point, to 
$£ 66.51$ or $4.06 \%$ after, indicating the positive effect seed contributions have on subsequent contributions. Next, we regressed the switch points of successful projects against multiple independent variables and found several that had a statistically significant effect on the switch point. Most notably, the number of backers and the average contribution in terms of proportion of goal (both before the switch, of course) had a large and positive (and marginally diminishing) effect. Qualitatively similar results emerged in the large data set as well. This suggests that the role seed money plays does not depend solely on the magnitude of it, but also on what it is composed of, a finding which provides further support to the signaling hypothesis. Regressions on unsuccessful projects, overall projects' success and a logistic regression on a binary variable for success or failure at achieving the goal provided further support to our findings.

The observed outcomes of crowd-funding projects are also consistent with the solutions

the theoretical model we presented predicts. Some projects raised no funds at all, which may indicate either the quality was too low for a contribution to be worthwhile to first movers, that they did not believe they could send a strong enough signal to evoke a response from others, or a combination of the two. Partial success may suggest the signal turned out to not be strong enough to elicit further contributions. In projects that raised exactly $100 \%$ of their goal the signal was just strong enough to make subsequent contributors want to see the project coming to fruition. Most of the successful projects exceeded their goal, indicating the seed contribution brought the perceived quality to a sufficiently high level that facilitated cooperation and led to overprovision.

In conclusion, the results of the empirical analysis provide strong support to our hypothesis regarding the effect of seed money on the success of a public good campaign, and are consistent with previous research and the theoretical model we presented. Early contributions convey a signal about a project's quality which affect subsequent contributions. The number of early contributors and their average contribution in terms of proportion of goal make out the signal.

\section{Conclusion}

The issue of financing the provision of public goods has been subject to widespread research in economic literature for many decades. In particular, the question of voluntary private contributions to public goods was written about extensively. Failure to coordinate contributions 
between participants, for example due to free rider or assurance problems or incomplete information regarding the quality of the good, can lead to under provision of the public good and loss of social welfare. It had been suggested (for example, Andreoni (1998), Bracha et al. (2011)) that early contributions to public good projects play a substantial role in affecting latter contributions and countering these issues. Early contributions, or seed money, may act as a signal of the public good's quality, desirability and likelihood of provision to hesitant potential backers (for example, Andreoni (2006), Potters et al. (2005, 2007)).

Due to the difficulty to acquire naturally-occurring data, empirical research in this field largely relied on laboratory experiments. However, we obtained a unique and granular data set of naturally-occurring data from a crowd-funding platform - a website dedicated to assist groups and individuals orchestrate the collection of a predefined amount for a specific purpose, mostly cultural goods. In crowd-funding campaigns, early contributors are likely to be acquainted with project creators, unlike latter supporters (Agrawal et al. (2011)). Hence, there's asymmetry in information contributors have, as early contributors are better informed about the quality of the good and the creators' ability to execute and deliver. We analyzed the data to examine the role of seed money and the hypothesis it conveys a signal to subsequent contributors. A second data set (Kickastarter), much larger in scope but less granular in information, was analyzed as well in order to replicate any findings.

First, a theoretical model was presented to characterize the interaction on crowd-funding platforms. In a single shot sequential public good game, a leader contributes seed money which serves as a signal of quality to an oblivious follower. While the leader knows the quality of the public good, she does not know exactly how the follower will interpret and respond to her signal. The asymmetric information each player has results in different outcomes to the game: no funds raised, part of the target goal raised, $100 \%$ of goal achieved and more than $100 \%$ collected.

Initial analysis of the granular data showed the observed various outcomes to crowdfunding campaigns are consistent with the possible solutions to the theoretical model. We found there is a large gap in success ratios between crowd-funding projects that were successful at reaching or passing their target goal and those that were unsuccessful at doing so, as the vast majority of unsuccessful projects raised less than $2 / 3$ of their goal. This gave us initial indication that after raising a certain threshold of proportion of goal campaigns are likely to succeed (which 
is in line with Andreoni (1998) and Granovetter's (1978) concepts of threshold based behavior). We then used Quandt's method (1958) to find whether we can differentiate between seed contributions and latter contributions to projects. For all but one project in our data we managed to do so, as we identified a statistically significant switch point, after which the contribution pattern changed course and switched to obey a different regime.

We found that successful projects experienced a switch at about 55\% of the target goal on average. After the switch, average contribution rose significantly and in more than one half of projects the velocity of contributions increased as well. This indicates increased willingness to contribute and confidence in the project, showing the positive effect seed contributions and the signal they carry have. This finding supports our hypothesis and is consistent with previous research and the theoretical model. A linear regression revealed that seed money is best explained by the number of contributors and the average contribution as proportion of goal they provide (positive and marginally diminishing effects). We see that the effect seed money has does not come solely from its magnitude, but also from its components, which supports our signaling hypothesis. Further analysis reinforces these findings. These findings were also qualitatively replicated on a much larger, albeit less granular, data set we analyzed.

The idea behind the switching point is that after a sufficient amount of resources invested in a certain project (number of investors and average investment by each person), the probability of fully funding the project has sufficiently increased. Thus, those wishing to invest in the project have now obtained a strong signal that (1) the quality is high, and (2) the project will be funded. This will give the potential investors an incentive to invest in the project. In addition, this would be a function of the quality of the projects. As projects are of higher quality, the average investment per investor will increase and the number of investors increase. The probability of funding the project increases as the number of investors and amount invested by each of them will increase. Therefore, we would see that over time, projects of higher quality funded while lower quality projects are not funded. The quality of the proposed products should increase and the switching point (in terms of average amount of investment by each person or number of investor) should decrease.

In conclusion, the empirical analysis provided substantial support to our hypothesis. Seed money encourages contributions and sends a signal to potential latter contributors about the quality 
of the public good. The findings indicate this signal in fact comprises two components: the average subjective evaluation of the good's quality and the number of people that share this evaluation. The empirical results are consistent with theory and suggested economic model. 


\section{References}

Agrawal, A., Catalini, C., Goldfarb, A., 2011. Friends, Family, and the Flat World: The Geography of Crowd-funding. NBER Working Paper No.16820.

Agrawal, A., Catalini, C., Goldfarb, A., 2013. Some Simple Economics of Crowdfunding. NBER Working Paper No.19133.

Andreoni, J., 1998. Toward a theory of charitable fund-raising. Journal of Political Economy 106 (6), 1186-1213.

Andreoni, J., 2006. Leadership giving in charitable fund-raising. Journal of Public Economic Theory 8 (1), 1-22.

Bracha, A., Minetti, M., Vesterlund, L., 2011. Seeds to succeed? Sequential giving to public projects. Journal of Public Economics 95, 416-427.

Brubaker, E.R., 1975. Free ride, free revelation, or golden rule? Journal of Law and Economics $18,147-161$.

Cadsby, C.B., Maynes, E., 1999. Voluntary provision of threshold public goods with continuous contributions: experimental evidence. Journal of Public Economics 71, 53-73.

Coats, J., Gronberg, T., Grosskopf, B., 2009. Simultaneous versus sequential public good provision and the role of refunds - an experimental study. Journal of Public Economics 93 (2009), 326-335.

Deutsch, J., 1992. Linear regression under two separate regimes: an empirical distribution for Quandt's log likelihood ratio. Applied Economics, 24, 123-127.

Erev, I., Rapoport, A., 1990. Provision of step-level public goods: the sequential contribution mechanism. Journal of Conflict Resolution 34 (3), 401-425.

Frey, B.S., Meier, S., 2004. Social comparisons and pro-social behavior: testing 'conditional cooperation' in a field experiment. The American Economic Review 94 (5), 1717-1722.

Granovetter, M., 1978. Threshold models of collective behavior. American Journal of Sociology, 83 (6), 1420-1443.

Hillman, A.L., 2009. Public Finance and Public Policy: Responsibilities and Limitations of Government, 2nd Ed. Cambridge University Press, New York NY.

Kappel, T. (2009), Ex Ante Crowd-funding and the Recording Industry: A Model for the U.S.?. Loyola of Los Angeles Entertainment Law Review 29: 375-385. 
Lambert, T. and Schwienbacher, A., 2010. An Empirical Analysis of Crowd-funding. Mimeo. Louvain School of Management, Belgium. Available at SSRN: http://ssrn.com/abstract=1578175.

List, J., Lucking-Reiley, D., 2002. The effects of seed money and refunds on charitable giving: experimental evidence from a university capital campaign. Journal of Political Economy 110 (1), 215-233.

Marks, M. and Croson, R., 1998. Alternative Rebate Rules in the Provision of a Threshold Public Good: An Experimental Investigation. Journal of Public Economics. 67, 195-220.

Palfrey, T.R., Rosenthal, H., 1984. Participation and the provision of discrete public goods: A strategic analysis. Journal of Public Economics 24 171-193.

Potters, J., Sefton, M., Vesterlund, L., 2005. After you - endogenous sequencing in voluntary contribution games. Journal of Public Economics 89 (8), 1399-1419.

Potters, J., Sefton, M., Vesterlund, L., 2007. Leading-by-example and signaling in voluntary contribution games: an experimental study. Economic Theory 33 (1), 169-182.

Quandt, R.W., 1958. The estimation of parameters of a linear regression system obeying two separate regimes. Journal of the American Statistical Association, 53, 873-80.

Samuelson, P.A., 1954. The Pure Theory of Public Expenditure. Review of Economics and Statistics, 36(4): 387-89.

Schmidtz, D., 1987. Contracts and public goods. Harvard Journal of Law and Public Policy 10, 475-503.

Spence, M., 1973. Job Market Signaling. Quarterly Journal of Economics, 87, 355-374.

Spencer, A.M., Swallow, A.K., Shogren, J.K., List, J.A., 2009. Rebate Rules in Threshold Public Good Provision. Journal of Public Economics, 93, 798-806.

Zhang, J., Liu, P., 2012. Rational Herding in Microloan Markets. Management Science, 58.5, 892-912. 


\section{Appendix}

\section{Appendix A - Appendix to the theoretical model}

\section{A1.1 Flow charts}

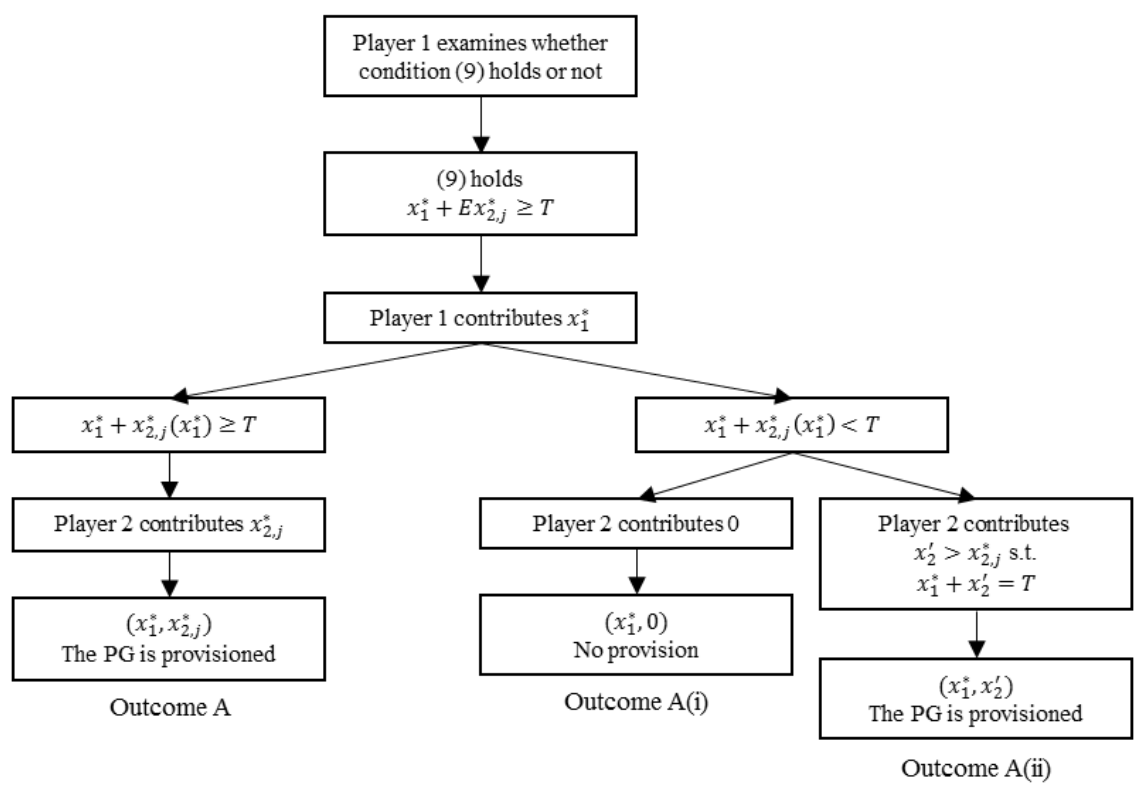

Figure 2a. Possible outcomes when condition (9) holds.

The possible outcomes under Case II are depicted in Figure $4 \mathrm{~b}$ on the next page. Note that if Player 1 chooses to contribute (the right branch), each sub branch can result in Player 2 contributing 0 due to budget/feasibility constraints. For practical reasons these cases were not included in the figure. 


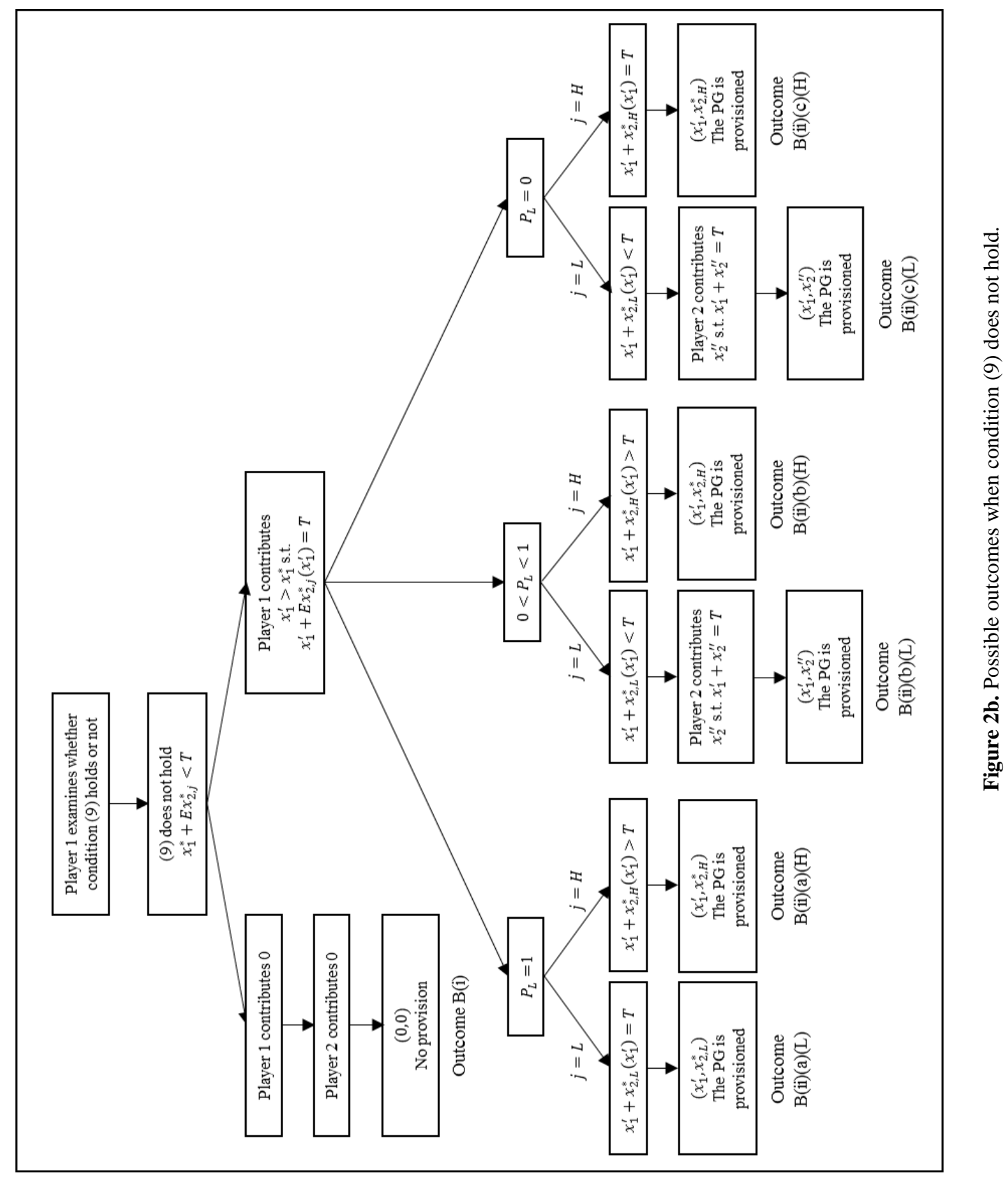




\section{A1.2 - Discussion of Case II}

Even in the case that condition (9) does not hold, there are scenarios where Player 1 can expect a payoff greater than 1 by making a contribution $x_{1}^{\prime}>x_{1}^{*}$. Player 1 believes that the best response of Player 2 to $x_{1}^{\prime}$ would be to complement her contribution to $T$ exactly. That is, $x_{1}^{\prime}+E x_{2, j}^{*}\left(x_{1}^{\prime}\right)=T, j=L, H$. We can replace $E x_{2, j}^{*}\left(x_{1}^{\prime}\right)$ using (5) for $j=L, H$ and the probabilities $P_{L}$ and. $P_{H}$. A few straightforward manipulations yield:

$$
x_{1}^{\prime}=\frac{4 T^{2}}{P_{L} \varphi_{L}^{2}+P_{H} \varphi_{H}^{2}}
$$

By plugging (14) in Player 2's BR function (5) we obtain:

$$
x_{2, j}^{*}\left(x_{1}^{\prime}\right)=\frac{\left(\varphi_{j}^{2}-4 T\right) T}{P_{L} \varphi_{L}^{2}+P_{H} \varphi_{H}^{2}}, \quad j=L, H
$$

The resulting total contribution can be expressed as:

$$
x_{1}^{\prime}+x_{2, j}^{*}\left(x_{1}^{\prime}\right)=\frac{\varphi_{j}^{2} T}{P_{L} \varphi_{L}^{2}+P_{H} \varphi_{H}^{2}}, \quad j=L, H
$$

If Player 2's true sensitivity to the signal is equal to or greater than the expected sensitivity in Player 1's view, there's a provision and even an over provision of the PG via Player 2's best response. Outcomes B(ii)(a)(L), B(ii)(a)(H), B(ii)(b)(H), B(ii)(c)(H) in Figure $2 b$ depict these cases. If Player 2's true sensitivity is less than the expected sensitivity, he may still compliment Player 1's contribution to meet $T$ exactly, in a similar fashion to outcome A(ii). In these cases, Player 2's contribution is given by:

$$
x_{2, L}^{\prime \prime}=T-\frac{4 T^{2}}{P_{L} \varphi_{L}^{2}+P_{H} \varphi_{H}^{2}}
$$

Outcomes B(ii)(b)(L), B(ii)(c)(L) depict these cases.

\section{$\underline{\text { A1.3 Expected and actual payoffs }}$}

A1.3.1 Outcome A - $\left(x_{1}^{*}, x_{2, j}^{*}\right)$

$$
\begin{gathered}
E \pi_{1}=1+\frac{m^{2}}{16 T}\left[P_{L} \varphi_{L}+P_{H} \varphi_{H}\right]^{2} \\
\pi_{2, j}^{e}=1+\frac{m^{2} \cdot\left[P_{L} \varphi_{L}+P_{H} \varphi_{H}\right]^{2} \cdot\left[\varphi_{j}^{2}+4 T\right]}{64 T^{2}}
\end{gathered}
$$




$$
\begin{gathered}
\pi_{1}\left(x_{1}^{*}, x_{2, j}^{*}\right)=1+\frac{m^{2}\left[P_{L} \varphi_{L}+P_{H} \varphi_{H}\right] \cdot\left[2 \varphi_{j}-\left(P_{L} \varphi_{L}+P_{H} \varphi_{H}\right)\right]}{16 T} \\
\pi_{2}\left(x_{1}^{*}, x_{2, j}^{*}\right)=1+\frac{m^{2} \cdot\left[P_{L} \varphi_{L}+P_{H} \varphi_{H}\right] \cdot\left[8 T \varphi_{j}-\left(\varphi_{j}^{2}-4 T\right)\left[P_{L} \varphi_{L}+P_{H} \varphi_{H}\right]\right]}{64 T^{2}}
\end{gathered}
$$

\section{A1.3.2 Outcome A(i) - $\left(x_{1}^{*}, 0\right)$}

Player 1 expects the outcome of the game to be as in outcome A, yet Player 2 actually contributes 0 . Player 1's expected payoff is given by (A4) and player 2's expected payoff equals his real payoff, which is 1 (from consuming the private good).

$$
\begin{gathered}
\pi_{2, j}\left(x_{1}^{*}, 0\right)=1 \\
\pi_{1}\left(x_{1}^{*}, 0\right)=1-x_{1}^{*}=1-\frac{m^{2}}{16 T}\left[P_{L} \varphi_{L}+P_{H} \varphi_{H}\right]^{2}
\end{gathered}
$$

\section{A1.3.3 Outcome A(ii) - $\left(x_{1}^{*}, x_{2, j}^{\prime}\right)$}

If the players contribute $\left(x_{1}^{*}, x_{2, j}^{\prime}\right)$ Player 1's expected payoff is still given by (A4).

$$
\begin{gathered}
\pi_{2, j}^{e}=1-T+x_{1}^{*}+\varphi_{j} \sqrt{x_{1}^{*}} \\
\pi_{1}\left(x_{1}^{*}, x_{2, j}^{\prime}\right)=1-\frac{m^{2}}{16 T}\left[P_{L} \varphi_{L}+P_{H} \varphi_{H}\right]^{2}+m \sqrt{T} \\
\pi_{2, j}\left(x_{1}^{*}, x_{2}^{\prime}\right)=1+\frac{m^{2}}{16 T}\left[P_{L} \varphi_{L}+P_{H} \varphi_{H}\right]^{2}-T m+m \sqrt{T}
\end{gathered}
$$

A1.3.4 Outcomes B(ii)(a)(L), B(ii)(a)(H), B(ii)(b)(H), B(ii)(c)(H) - $\left(x_{1}^{\prime}, x_{2, j}^{*}\left(x_{1}^{\prime}\right)\right)$

$$
\begin{gathered}
E \pi_{1}=1-\frac{4 T^{2}}{P_{L} \varphi_{L}^{2}+P_{H} \varphi_{H}^{2}}+m \sqrt{T} \\
\pi_{2, j}^{e}\left(x_{1}^{\prime}, x_{2, j}^{*}\left(x_{1}^{\prime}\right)\right)=1+\frac{4 T^{2}}{P_{L} \varphi_{L}^{2}+P_{H} \varphi_{H}^{2}}+\frac{T \varphi_{j}^{2}}{P_{L} \varphi_{L}^{2}+P_{H} \varphi_{H}^{2}} \\
\pi_{1}\left(x_{1}^{\prime}, x_{2, j}^{*}\left(x_{1}^{\prime}\right)\right)=1-\frac{4 T^{2}}{P_{L} \varphi_{L}^{2}+P_{H} \varphi_{H}^{2}}+\frac{m \varphi_{j} \sqrt{T}}{\sqrt{P_{L} \varphi_{L}^{2}+P_{H} \varphi_{H}^{2}}}
\end{gathered}
$$




$$
\pi_{2, j}\left(x_{1}^{\prime}, x_{2, j}^{*}\left(x_{1}^{\prime}\right)\right)=1-\frac{\left(\varphi_{j}^{2}-4 T\right) T}{P_{L} \varphi_{L}^{2}+P_{H} \varphi_{H}^{2}}+\frac{m \varphi_{j} \sqrt{T}}{\sqrt{P_{L} \varphi_{L}^{2}+P_{H} \varphi_{H}^{2}}}
$$

\section{A1.3.5 Outcomes B(ii)(b)(L), B(ii)(c)(L) - $\left(x_{1}^{\prime}, x_{2, L}^{\prime \prime}\right)$}

Player 1's expected profit remains as we've seen in (A13).

$$
\begin{gathered}
\pi_{2, L}^{e}\left(x_{1}^{\prime}, x_{2, L}^{\prime \prime}\right)=1+\frac{4 T^{2}}{P_{L} \varphi_{L}^{2}+P_{H} \varphi_{H}^{2}}-T+\frac{2 T \varphi_{L}}{\sqrt{P_{L} \varphi_{L}^{2}+P_{H} \varphi_{H}^{2}}} \\
\pi_{1}\left(x_{1}^{\prime}, x_{2, L}^{\prime \prime}\right)=1-\frac{4 T^{2}}{P_{L} \varphi_{L}^{2}+P_{H} \varphi_{H}^{2}}+m \sqrt{T} \\
\pi_{2}\left(x_{1}^{\prime}, x_{2, L}^{\prime \prime}\right)=1+\frac{4 T^{2}}{P_{L} \varphi_{L}^{2}+P_{H} \varphi_{H}^{2}}-T+m \sqrt{T}
\end{gathered}
$$

\section{$\underline{\text { Appendix B - Appendix to the empirical analysis }}$}

\section{B1. Frequency of projects by category - Sponsume data}

\begin{tabular}{|l|r|}
\hline Category & Frequency \\
\hline Film & 203 \\
\hline Performing Arts & 158 \\
\hline Music & 60 \\
\hline Fine Arts & 42 \\
\hline Documentary & 40 \\
\hline Event & 26 \\
\hline Social Enterprise & 21 \\
\hline Photography & 20 \\
\hline Publishing & 14 \\
\hline Sport & 10 \\
\hline Enterprise & 10 \\
\hline Education & 9 \\
\hline Green & 8 \\
\hline
\end{tabular}

\begin{tabular}{|l|r|}
\hline Category & Frequency \\
\hline Technology & 6 \\
\hline Comics & 5 \\
\hline Fashion & 5 \\
\hline Quirky & 5 \\
\hline Transmedia & 5 \\
\hline Design & 4 \\
\hline Crafts & 3 \\
\hline Gaming & 3 \\
\hline Heritage & 2 \\
\hline Invention & 2 \\
\hline Food & 1 \\
\hline & \\
\hline Total & 662 \\
\hline
\end{tabular}

Table 4. 
B2. Descriptive stats on 287 remaining projects - Sponsume data

\begin{tabular}{|c|c|c|c|c|c|c|c|c|}
\hline & & Obs. & Mean & SD & Min & Max & Median & Mode \\
\hline \multirow[t]{3}{*}{ Goal (GBP) } & All projects & 287 & 3316.05 & 4412.13 & 200 & 50000 & 2000 & 2000 \\
\hline & Successful Projects & 143 & 2353.38 & 2991.91 & 200 & 25000 & 1500 & 1000 \\
\hline & Unsuccessful Projects & 144 & 4272.04 & 5310.17 & 200 & 50000 & 3000 & 3000 \\
\hline \multirow[t]{3}{*}{ Funds Raised (GBP) } & All projects & 287 & 1965.49 & 2595.70 & 134 & 27301 & 1160 & 750 \\
\hline & Successful Projects & 143 & 2635.99 & 3258.13 & 225 & 27301 & 1575 & 1000 \\
\hline & Unsuccessful Projects & 144 & 1299.64 & 1427.62 & 134 & 10828 & 866.5 & 310 \\
\hline \multirow[t]{3}{*}{ Success \% } & All projects & 287 & 0.78 & 0.48 & 0.02 & 4.22 & 0.9828 & 1 \\
\hline & Successful Projects & 143 & 1.16 & 0.35 & 1 & 4.22 & 1.05 & 1 \\
\hline & Unsuccessful Projects & 144 & 0.40 & 0.24 & 0.02 & 0.9828 & 0.3727 & 0.583 \\
\hline \multirow[t]{3}{*}{ Number of Backers } & All projects & 287 & 43.17 & 37.01 & 15 & 386 & 32 & 23 \\
\hline & Successful Projects & 143 & 50.66 & 36.28 & 15 & 214 & 40 & 23 \\
\hline & Unsuccessful Projects & 144 & 35.72 & 36.35 & 15 & 386 & 28 & 16 \\
\hline Average & All projects & 287 & 42.49 & 28.71 & 8.59 & 176.47 & 33.93 & 80 \\
\hline \multirow[t]{2}{*}{ Contribution (GBP) } & Successful Projects & 143 & 48.95 & 33.25 & 8.59 & 176.47 & 38.52 & 22.73 \\
\hline & Unsuccessful Projects & 144 & 36.07 & 21.63 & 8.92 & 139.55 & 31.34 & 29.58 \\
\hline
\end{tabular}

\begin{tabular}{|l|l|l|l|l|l|l|l|l|}
\cline { 2 - 9 } \multicolumn{2}{c|}{} & Obs. & Mean & SD & Min & Max & Median & Mode \\
\hline \multirow{3}{*}{ Goal (GBP) } & All projects & 287 & 3316.05 & 4412.13 & 200 & 50000 & 2000 & 2000 \\
\cline { 2 - 9 } & Successful Projects & 143 & 2353.38 & 2991.91 & 200 & 25000 & 1500 & 1000 \\
\cline { 2 - 9 } & Unsuccessful Projects & 144 & 4272.04 & 5310.17 & 200 & 50000 & 3000 & 3000 \\
\hline \multirow{3}{*}{$\begin{array}{l}\text { Funds Raised } \\
\text { (GBP) }\end{array}$} & All projects & 287 & 1965.49 & 2595.7 & 134 & 27301 & 1160 & 750 \\
\cline { 2 - 9 } & Successful Projects & 143 & 2635.99 & 3258.13 & 225 & 27301 & 1575 & 1000 \\
\cline { 2 - 9 } & Unsuccessful Projects & 144 & 1299.64 & 1427.62 & 134 & 10828 & 866.5 & 310 \\
\hline \multirow{3}{*}{ Success \% } & All projects & 287 & 0.78 & 0.48 & 0.02 & 4.22 & 0.9828 & 1 \\
\cline { 2 - 9 } & Successful Projects & 143 & 1.16 & 0.35 & 1 & 4.22 & 1.05 & 1 \\
\cline { 2 - 9 } & Unsuccessful Projects & 144 & 0.4 & 0.24 & 0.02 & 0.9828 & 0.3727 & 0.583 \\
\hline
\end{tabular}




\begin{tabular}{|l|l|l|l|l|l|l|l|l|}
\hline \multirow{2}{*}{$\begin{array}{l}\text { Number of } \\
\text { Backers }\end{array}$} & All projects & 287 & 43.17 & 37.01 & 15 & 386 & 32 & 23 \\
\cline { 2 - 9 } & Successful Projects & 143 & 50.66 & 36.28 & 15 & 214 & 40 & 23 \\
\cline { 2 - 9 } & Unsuccessful Projects & 144 & 35.72 & 36.35 & 15 & 386 & 28 & 16 \\
\hline \begin{tabular}{l} 
Average $\begin{array}{l}\text { Contribution } \\
\text { (GBP) }\end{array}$ \\
\cline { 2 - 9 }
\end{tabular} & All projects & 287 & 42.49 & 28.71 & 8.59 & 176.47 & 33.93 & 80 \\
\cline { 2 - 9 } & Successful Projects & 143 & 48.95 & 33.25 & 8.59 & 176.47 & 38.52 & 22.73 \\
\cline { 2 - 9 }
\end{tabular}

Table 5.

\section{$\underline{\text { B3. Descriptive stats on } 18088 \text { Kickstarter Projects }}$}

\begin{tabular}{|c|c|c|c|c|c|c|c|c|}
\hline & \\
\hline & & Obs. & Mean & SD & Min & Max & Median & Mode \\
\hline \multirow{3}{*}{ Goal (USD) } & All Projects & 18088 & 24462.64 & 196310.02 & 0.63 & 10500000.00 & 5000.00 & 5000 \\
\hline & Successful Projects & 9095 & 8601.23 & 21757.64 & 0.63 & 1000000.00 & 3500.00 & 5000 \\
\hline & Unsuccessful Projects & 8993 & 40503.94 & 276633.51 & 1.00 & 10500000.00 & 6000.00 & 5000 \\
\hline \multirow{3}{*}{$\begin{array}{l}\text { Funds } \\
\text { Raised } \\
\text { (USD) }\end{array}$} & All Projects & 18088 & 5985.29 & 21427.27 & 0.00 & 1505367.00 & 1292.50 & 0 \\
\hline & Successful Projects & 9095 & 10518.96 & 29076.91 & 1.00 & 1505367.00 & 4176.00 & 2000 \\
\hline & Unsuccessful Projects & 8993 & 1400.20 & 5161.70 & 0.00 & 146022.00 & 136.00 & 0 \\
\hline \multirow{3}{*}{$\begin{array}{l}\text { Success } \\
\text { Ratio }\end{array}$} & All Projects & 18088 & 0.71 & 0.95 & 0.00 & 47.23 & 1.00 & 0 \\
\hline & Successful Projects & 9095 & 1.32 & 1.01 & 1.00 & 47.23 & 1.10 & 1 \\
\hline & Unsuccessful Projects & 8993 & 0.10 & 0.16 & 0.00 & 1.00 & 0.03 & 0 \\
\hline \multirow{3}{*}{$\begin{array}{l}\text { Number of } \\
\text { Backers }\end{array}$} & All Projects & 18088 & 73.20 & 290.13 & 0.00 & 17713.00 & 24.00 & 0 \\
\hline & Successful Projects & 9095 & 129.81 & 399.15 & 1.00 & 17713.00 & 60.00 & 18 \\
\hline & Unsuccessful Projects & 8993 & 15.96 & 40.87 & 0.00 & 1199.00 & 4.00 & 0 \\
\hline \multirow{3}{*}{$\begin{array}{l}\text { Average } \\
\text { Contribution } \\
\text { (USD) }\end{array}$} & All Projects & 18088 & 69.98 & 148.19 & 0.00 & 10000.00 & 49.18 & 0 \\
\hline & Successful Projects & 9095 & 86.39 & 127.49 & 1.00 & 9000.00 & 65.33 & 50 \\
\hline & Unsuccessful Projects & 8993 & 53.38 & 164.89 & 0.00 & 10000.00 & 28.13 & 0 \\
\hline
\end{tabular}

Table 6. 


\section{B4. Descriptive stats on switch points - Kickstarter data}

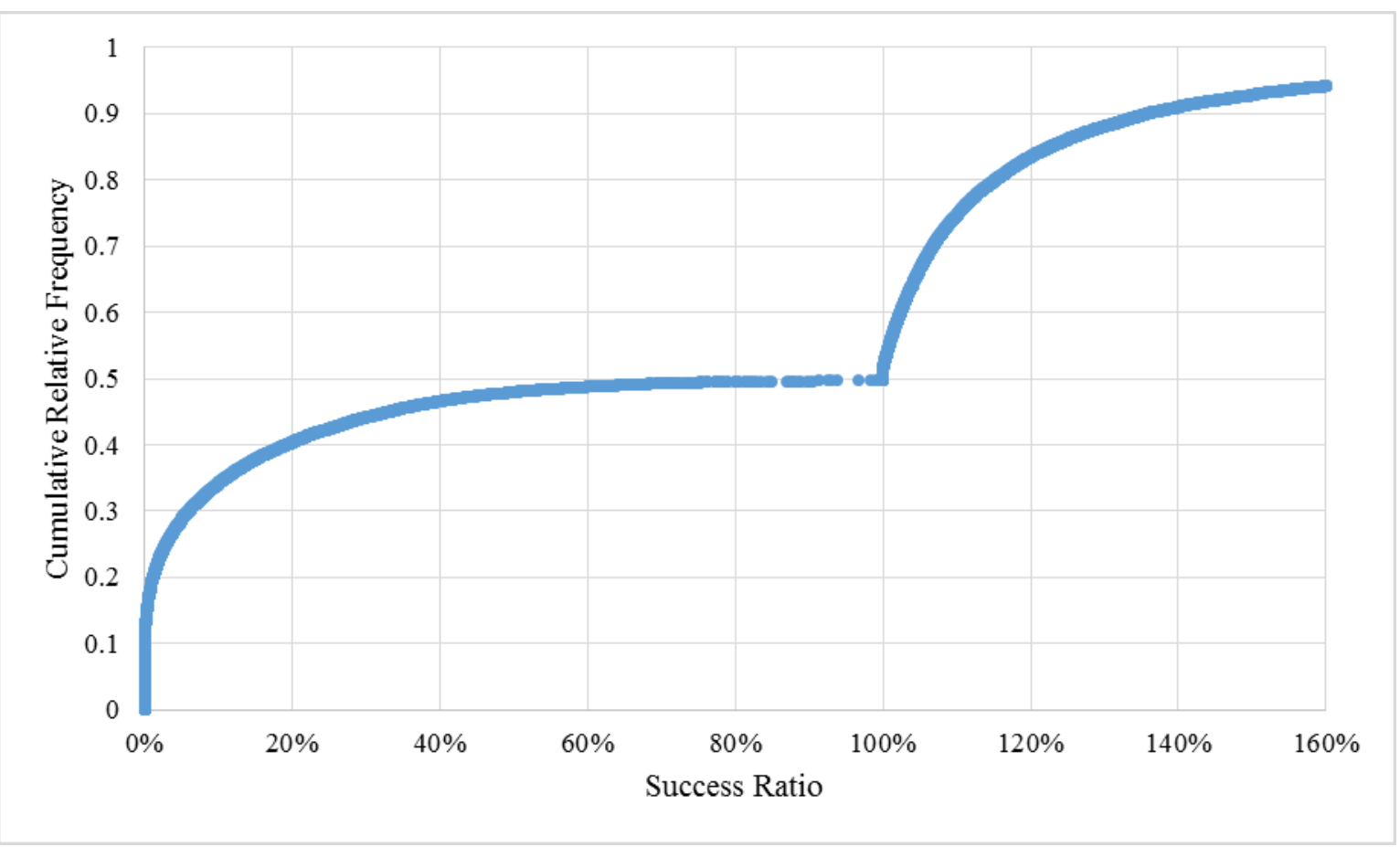

Figure 3 Cumulative relative frequency of success ratios. For ease of presentation, the horizontal axis was trimmed at $160 \%$,

B5. Descriptive stats on switch points and histograms - Sponsume data

$\overline{\text { Successful }}$

$\begin{array}{lr}\text { Mean } & 0.548857746 \\ \text { Standard Error } & 0.023772941 \\ \text { Median } & 0.5225 \\ \text { Mode } & 0.4 \\ \text { Standard Deviation } & 0.283287286 \\ \text { Sample Variance } & 0.080251687 \\ \text { Kurtosis } & 0.320785046 \\ \text { Skewness } & 0.689842319 \\ \text { Range } & 1.312 \\ \text { Minimum } & 0.066 \\ \text { Maximum } & 1.378 \\ \text { Sum } & 77.9378 \\ \text { Count } & 142 \\ \text { Confidence } & \\ \text { Level(95.0\%) } & \end{array}$

Table 7a.

\begin{tabular}{lr}
\hline \multicolumn{2}{c}{ Unsuccessful } \\
\hline \\
Mean & 0.180350694 \\
Standard Error & 0.011967545 \\
Median & 0.147 \\
Mode & 0.053 \\
Standard Deviation & 0.143610538 \\
Sample Variance & 0.020623987 \\
Kurtosis & 2.185521282 \\
Skewness & 1.330393443 \\
Range & 0.752 \\
Minimum & 0.001 \\
Maximum & 0.753 \\
Sum & 25.9705 \\
Count & 144 \\
Confidence & \\
Level(95.0\%) & \\
\hline Table 7b. & 0.023656153 \\
\hline
\end{tabular}



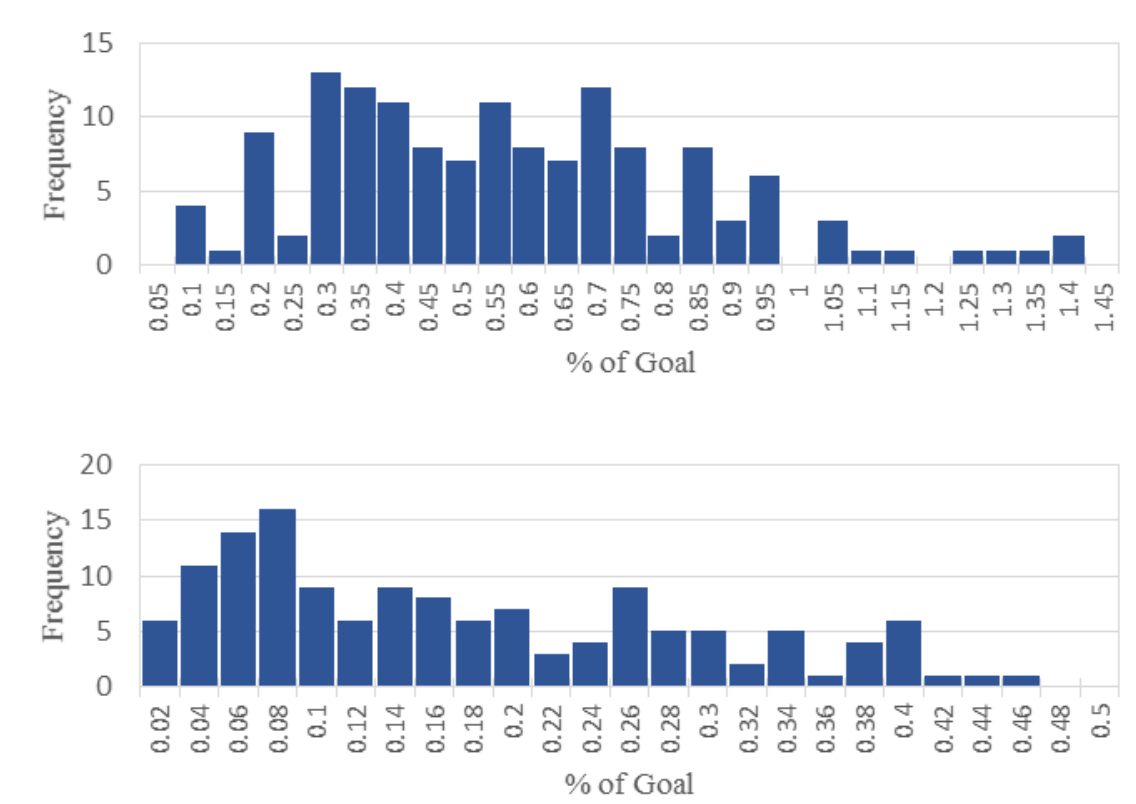

Figure 4a (top) and $\mathbf{4 b}$. The top figure depicts the distribution of switch point of successful projects. The bottom figure depicts the distribution for unsuccessful projects. For ease of presentation, 5 observations were dropped from the bottom figure: 3 between $56 \%-58 \%$, one between $70 \%-72 \%$ and one between $74 \%-76 \%$. 


\section{Appendix B6}

\begin{tabular}{|l|l|l|l|}
\hline & Successful & Unsuccessful & All \\
\hline \hline $\mathrm{n}$ & 142 & 144 & 286 \\
\hline Goal GBP* & 2367.61 & 4272.04 & 3326.48 \\
& $(2,997.64)$ & $(5,310.17)$ & $(4,416.32)$ \\
\hline Funds raised GBP* & 2651.79 & 1299.64 & 1970.99 \\
& $(3,264.17)$ & $(1,427.62)$ & $(2,598.58)$ \\
\hline Success ratio* & 1.16 & 0.40 & 0.78 \\
& $(0.35)$ & $(0.24)$ & $(0.48)$ \\
\hline Number of backers* & 50.87 & 35.72 & 43.24 \\
\hline Project's span (days)* & $(36.33)$ & $(36.35)$ & $(37.06)$ \\
\hline Switch point* & 45.39 & 53.27 & 49.36 \\
\hline Amount raised up to the switch GBP* & $(22.98)$ & $(24.29)$ & $(23.93)$ \\
\hline Average contribution GBP* & 0.5489 & 0.1804 & 0.3633 \\
& $(0.2833)$ & $(0.1436)$ & $(0.2900)$ \\
\hline Average contribution as proportion of goal* & 1242.32 & 576.21 & 906.94 \\
& $(1,583.68)$ & $(712.18)$ & $(1,267.52)$ \\
\hline Total contributions after the switch GBP** & 49.17 & 36.07 & 42.58 \\
& $(33.26)$ & $(21.63)$ & $(28.72)$ \\
\hline Total contributions after the switch as proportion of goal** & 0.0322 & 0.0142 & 0.0231 \\
& $(0.0184)$ & $(0.0112)$ & $(0.0177)$ \\
\hline Days from start day until the switch & 1409.47 & 723.43 & 1064.05 \\
& $(2,161.83)$ & $(952.60)$ & $(1,698.69)$ \\
\hline Days to switch as proportion of span & $(0.3417)$ & 0.2180 & 0.4135 \\
& 21.14 & $23.1572)$ & $(0.3303)$ \\
\hline Average contribution in the first two days GBP* & $(21.14)$ & $(22.11)$ & 22.23 \\
\hline Average contribution in the first two days as proportion of & 0.4730 & 0.4348 & 0.4537 \\
goal* & $(0.3397)$ & $(0.3183)$ & $(0.3290)$ \\
\hline
\end{tabular}

Table 8. Key measures for successful and unsuccessful projects. Standard deviations are in parenthesis. * indicates the difference between means is statistically significant at the $5 \%$ significance level. ** As total contributions can pass the target goal, total contributions after the switch in GBP do not necessarily equal the goal minus the amount raised up to the switch. Similarly, total contributions after the switch as proportion of goal do not necessarily equal 1 minus the switch point.

\section{Appendix B7. Regression of switch points of unsuccessful projects - Sponsume data}

We regressed the switch point of unsuccessful projects against the same set of variables which had a statistically significant effect on the switch point of successful projects. 


\begin{tabular}{|c|c|c|c|c|c|c|}
\hline switch point & Coef. & Std. Err. & $\mathrm{t}$ & $\mathrm{P}>|\mathrm{t}|$ & [95\% Conf. & Interval] \\
\hline $\begin{array}{l}\text { Average contribution before the } \\
\text { switch as proportion of goal }\end{array}$ & $16.90399 *$ & 1.685967 & 10.03 & 0.000 & 13.56944 & 20.23854 \\
\hline $\begin{array}{l}\text { Average contributions before the } \\
\text { switch as proportion of goal } \\
\text { squared }\end{array}$ & $-164.5519 *$ & 34.63148 & -4.75 & 0.000 & -233.047 & -96.05688 \\
\hline Backers before the switch & $0.0084547^{*}$ & 0.0007667 & 11.03 & 0.000 & 0.0069383 & 0.0099712 \\
\hline Backers before the switch squared & $-0.0000339^{*}$ & 4.35E-06 & -7.78 & 0.000 & -0.0000425 & -0.0000253 \\
\hline $\begin{array}{l}\text { Total contributions in first two } \\
\text { days as proportion of goal }\end{array}$ & $0.3644686^{*}$ & 0.0864112 & 4.22 & 0.000 & 0.1935622 & 0.5353749 \\
\hline Goal GBP & $-4.95 \mathrm{E}-07$ & $1.06 \mathrm{E}-06$ & -0.47 & 0.641 & $-2.59 \mathrm{E}-06$ & $1.60 \mathrm{E}-06$ \\
\hline $\begin{array}{l}\text { Days to switch as proportion of } \\
\text { span }\end{array}$ & $0.0541111 *$ & 0.019103 & 2.83 & 0.005 & 0.0163288 & 0.0918934 \\
\hline Value of highest perk GBP & 3.39E-06 & $4.46 \mathrm{E}-06$ & 0.76 & 0.449 & $-5.44 \mathrm{E}-06$ & 0.0000122 \\
\hline Value of the median perk GBP & 0.000048 & 0.000164 & 0.29 & 0.770 & -0.0002764 & 0.0003724 \\
\hline _cons & -0.1546277 & 0.0201229 & -7.68 & 0.000 & -0.1944273 & -0.1148281 \\
\hline
\end{tabular}

Table 9. A linear regression on unsuccessful projects' switch points. Coefficients marked by * are statistically significant at the $5 \%$ significance level. Adjusted $R^{2}=84.35 \%$.

Next, we looked for the set of variables which have a statistically significant effect on the unsuccessful projects and arrived at the following, very similar, result:

\begin{tabular}{l|rrrrrr}
\hline switch point & Coef. & Std. Err. & $\mathrm{t}$ & $\mathrm{P}>|\mathrm{t}|$ & [95\% Conf. & Interval] \\
\hline $\begin{array}{l}\text { Average contribution before the } \\
\text { switch as proportion of goal }\end{array}$ & $16.89238^{*}$ & 1.530101 & 11.04 & 0.000 & 13.86671 & 19.91805 \\
$\begin{array}{l}\text { Average contributions before the } \\
\text { switch as proportion of goal } \\
\text { squared }\end{array}$ & $-165.9589^{*}$ & 32.46948 & -5.11 & 0.000 & -230.165 & -101.7527 \\
Backers before the switch & & & & & & \\
Backers before the switch squared & $-0.0083307^{*}$ & 0.0007467 & 11.16 & 0.000 & 0.0068542 & 0.0098072 \\
$\begin{array}{l}\text { Total contributions in first two } \\
\text { days as proportion of goal }\end{array}$ & $0.3634358^{*}$ & 0.0856636 & 4.24 & 0.000 & 0.1940418 & 0.5328298 \\
$\begin{array}{l}\text { Days to switch as proportion of } \\
\text { span }\end{array}$ & $0.0574712^{*}$ & 0.0186036 & 3.09 & 0.002 & 0.0206838 & 0.0942586 \\
cons & $-0.1507657^{*}$ & 0.0151702 & -9.94 & 0.000 & -0.1807637 & -0.1207676 \\
\hline
\end{tabular}

Table 10. * indicates the coefficient is statistically significant at the 5\% significance level. Adjusted $R^{2}=84.56 \%$ 
Appendix B8. Correlation matrix for highest and median valued perks and the goal -

Sponsume data

\begin{tabular}{lrrr}
\hline & Goal GBP & $\begin{array}{c}\text { Value of highest } \\
\text { perk GBP }\end{array}$ & $\begin{array}{c}\text { Value of the median } \\
\text { perk GBP }\end{array}$ \\
\hline Goal GBP & 1 & & \\
Value of highest perk GBP & -0.03122822 & 1 & 1 \\
Value of the median perk GBP & 0.318136949 & -0.017284534 & \\
\hline Table 11.
\end{tabular}

Table 11

\section{Appendix B9. Further regressions on Sponsume Data}

Logit on successful - yes / no:

Log likelihood $=-46.847916 \quad$ Pseudo R2 $\quad=\quad 0.7637$

\begin{tabular}{|c|c|c|c|c|c|c|}
\hline Successful & Coef. & Std. Err. & $\mathrm{z}$ & $\mathrm{P}>|\mathrm{z}|$ & [95\% Conf. & Interval] \\
\hline Number of backers & $.4716439^{*}$ & .0873627 & 5.40 & 0.000 & .3004161 & .6428716 \\
\hline Number of backers squared & $-.0016995^{*}$ & .0003358 & -5.06 & 0.000 & -.0023575 & -.0010414 \\
\hline $\begin{array}{l}\text { Average contribution before the } \\
\text { switch as proportion of goal }\end{array}$ & $404.8197 *$ & 92.17239 & 4.39 & 0.000 & 224.1652 & 585.4743 \\
\hline $\begin{array}{l}\text { Average contribution after the } \\
\text { switch as proportion of goal }\end{array}$ & $291.4129 *$ & 65.64209 & 4.44 & 0.000 & 162.7567 & 420.069 \\
\hline $\begin{array}{l}\text { Average contribution before the } \\
\text { switch as proportion of goal squared }\end{array}$ & $-2295.675^{*}$ & 709.5814 & -3.24 & 0.001 & -3686.429 & -904.9211 \\
\hline $\begin{array}{l}\text { Average contribution after the } \\
\text { switch as proportion of goal squared }\end{array}$ & $-1629.285^{*}$ & 405.001 & -4.02 & 0.000 & -2423.072 & -835.4978 \\
\hline $\begin{array}{l}\text { Average contribution after the } \\
\text { switch-before the switch ratio }\end{array}$ & $.7160627^{*}$ & .3080017 & 2.32 & 0.020 & .1123905 & 1.319735 \\
\hline Days to switch as proportion of span & -1.496149 & .8487651 & -1.76 & 0.078 & -3.159698 & .1674 \\
\hline _cons & $-30.36827^{*}$ & 5.484819 & -5.54 & 0.000 & -41.11832 & -19.61822 \\
\hline
\end{tabular}

Table 12. * indicates the coefficient is statistically significant at the 5\% significance level. 
We also ran a linear regression to examine the variables affecting the overall success ratio of a project.

\begin{tabular}{l|llllll}
\hline Success Ratio & Coef. & Std. Err. & $\mathrm{t}$ & $\mathrm{P}>|\mathrm{t}|$ & {$[95 \%$ Conf. } & Interval] \\
\hline \hline Goal GBP & $-9.15 \mathrm{e}-06^{*}$ & $3.58 \mathrm{e}-06$ & -2.55 & 0.011 & -.0000162 & $-2.09 \mathrm{e}-06$ \\
Backers before the switch & $.0168059^{*}$ & .0015206 & 11.05 & 0.000 & .0138125 & .0197993 \\
Backers before the switch squared & $-.000053^{*}$ & $9.57 \mathrm{e}-06$ & -5.54 & 0.000 & -.0000718 & -.0000342 \\
$\begin{array}{l}\text { Average contribution before the } \\
\text { switch as proportion of goal }\end{array}$ & $17.53591^{*}$ & 2.443508 & 7.18 & 0.000 & 12.72556 & 22.34627 \\
$\begin{array}{l}\text { Average contribution before the } \\
\text { switch as proportion of goal squared }\end{array}$ & $-99.2211^{*}$ & 25.4432 & -3.90 & 0.000 & -149.3093 & -49.13291 \\
$\begin{array}{l}\text { Backers after the switch } \\
\text { Backers after the switch squared }\end{array}$ & $.0201789^{*}$ & .0016309 & 12.37 & 0.000 & .0169682 & .0233896 \\
$\begin{array}{l}\text { Average contribution after the } \\
\text { switch as proportion of goal }\end{array}$ & $-.0001023^{*}$ & .0000102 & -10.00 & 0.000 & -.0001224 & -.0000822 \\
$\begin{array}{l}\text { Average contribution after the } \\
\text { switch as proportion of goal squared }\end{array}$ & $-10.15691^{*}$ & 1.953086 & 10.32 & 0.000 & 16.31202 & 24.00181 \\
$\begin{array}{l}\text { Days to switch as proportion of span } \\
\text { cons }\end{array}$ & $-.1303099^{*}$ & .04989 & -2.61 & 0.009 & -.2285248 & -.032095 \\
\hline
\end{tabular}

Table 13. * indicates the coefficient is statistically significant at the 5\% significance level. Adjusted $R^{2}=80.15 \%$ 


\section{Appendix B10. Regressions on Kickstarter Data}

\begin{tabular}{|c|c|c|c|c|c|c|}
\hline Success Ratio & Coef. & Std. Err. & $\mathrm{t}$ & $\mathrm{P}>|\mathrm{t}|$ & [95\% Conf. & Interval] \\
\hline _cons & "-0.014633 & 0.01769617 & $\overline{c-0.83}$ & 0.408 & "-0.049324314 & 0.020057354 \\
\hline $\begin{array}{l}\text { Average contributio } \\
\text { before the switch as } \\
\text { proportion of goal }\end{array}$ & $14.808551 *$ & 0.51629877 & 28.68 & 0.000 & 13.79642068 & 15.8206818 \\
\hline $\begin{array}{l}\text { Average contributio } \\
\text { before the switch as } \\
\text { proportion of goal } \\
\text { squared }\end{array}$ & $-34.371867 *$ & 3.12367348 & -11.00 & 0.000 & -40.49538649 & -28.24834826 \\
\hline $\begin{array}{l}\text { Backers before the } \\
\text { switch }\end{array}$ & $0.001072 *$ & $4.1231 \mathrm{E}-05$ & 26.00 & 0.000 & 0.000991228 & 0.001152884 \\
\hline $\begin{array}{l}\text { Backers before the } \\
\text { switch squared }\end{array}$ & $0.000000 *$ & 4.363E-09 & -19.43 & 0.000 & $-9.33349 \mathrm{E}-08$ & $-7.62289 \mathrm{E}-08$ \\
\hline $\begin{array}{l}\text { Total contributions } \\
\text { first two days as } \\
\text { proportion of goal }\end{array}$ & $1.038163^{*}$ & 0.01708232 & 60.77 & 0.000 & 1.004675806 & 1.071650727 \\
\hline Goal USD & $-0.000004^{*}$ & 2.7433E-07 & -14.24 & 0.000 & $-4.44388 \mathrm{E}-06$ & $-3.3683 \mathrm{E}-06$ \\
\hline $\begin{array}{l}\text { Days to switch as } \\
\text { proportion of span }\end{array}$ & $0.489616 *$ & 0.02961203 & 16.53 & 0.000 & 0.431565778 & 0.54766615 \\
\hline
\end{tabular}

Table 14. Output of a standard linear regression on the switch points of successful projects in the Kickstarter data set. * indicates the coefficient is statistically significant at the $5 \%$ significance level. Adjusted $R^{2}=57.34 \%$ 


\begin{tabular}{l|llllll}
\hline Success Ratio & Coef. & Std. Err. & $\mathrm{t}$ & $\mathrm{P}>|\mathrm{t}|$ & {$[95 \%$ Conf. } & Interval] \\
\hline \hline _cons & -0.064246 & 0.00470343 & -13.66 & 0.000 & -0.073472778 & -0.055018918 \\
$\begin{array}{l}\text { Average contribution } \\
\text { before the switch as } \\
\text { proportion of goal }\end{array}$ & 18.146212 & 0.5532521 & 32.80 & 0.000 & 17.06087209 & 19.2315529 \\
$\begin{array}{l}\text { Average contributions } \\
\text { before the switch as } \\
\text { proportion of goal } \\
\text { squared }\end{array}$ & -173.978684 & 13.2328913 & -13.15 & 0.000 & -199.9382627 & -148.0191045 \\
$\begin{array}{l}\text { Backers before the } \\
\text { switch }\end{array}$ & 0.001589 & $7.2105 \mathrm{E}-05$ & 22.04 & 0.000 & 0.001447822 & 0.001730726 \\
$\begin{array}{l}\text { Backers before the } \\
\text { switch squared }\end{array}$ & -0.000002 & $1.3944 \mathrm{E}-07$ & -17.12 & 0.000 & $-2.66133 \mathrm{E}-06$ & $-2.11423 \mathrm{E}-06$ \\
$\begin{array}{l}\text { Total contributions in } \\
\text { first two days as } \\
\text { proportion of goal }\end{array}$ & 0.432232 & 0.03429064 & 12.60 & 0.000 & 0.364961961 & 0.499501057 \\
$\begin{array}{l}\text { Goal USD } \\
\begin{array}{l}\text { Days to switch as } \\
\text { proportion of span }\end{array}\end{array}$ & 0.000000 & $6.6168 \mathrm{E}-09$ & -2.74 & 0.006 & $-3.11139 \mathrm{E}-08$ & $-5.15286 \mathrm{E}-09$ \\
\hline
\end{tabular}

Table 15. Output of a standard linear regression on the switch points of unsuccessful projects in the Kickstarter data set. * indicates the coefficient is statistically significant at the 5\% significance level. Adjusted $R^{2}=70.97 \%$ 